ENVIRONMENTAL RESTORATION PROGRAM
ORNL/ER-35

087

MARO 01902

Surface Radiological Investigation of Trench 5 in Waste Area Grouping 7 at Oak Ridge National Laboratory, Oak Ridge, Tennessee

D. D. Goff 
This report has been reproduced directly from the best available copy.

Available to DOE and DOE contractors from the Office of Sclentific and Technical Information, P.O. Box 62, Oak Aldge, TN 37831; prices avallable from 615-576-8401, FTS 626-8401.

Avallabie to the public from the National Technical Information Service, U.S. Department of Commerce, 5285 Port Royal Rd., Springfield, VA 22161.

\section{DISCLAIMER}

This report was prepared as an account of work sponsored by an agency of the United States Government. Neither the United States Government nor any agency thereof, nor any of their employess, makes any warranty, express or implied, or assumes any legal liability or responsibility for the accuracy, completeness, or usefulness of any information, apparatus, product, or process disclosed, or represents that its use would not infringe privately owned rights. Reference herein to any specific commercial product, process, or service by trade name, trademark, manufacturer, or otherwise does not necessarily constitute or imply its endorsement, recommendation, or favoring by the United States Government or any agency thercof. The viows and opinions of authors expressed herein do not necessarily state or reflect those of the United States Government or any agency thereof. 


\author{
Environmental Restoration Division \\ ORNL Environmental Restoration Program
}

\title{
Surface Radiological Investigation of Trench 5 in Waste Area Grouping 7 at Oak Ridge National Laboratory, Oak Ridge, Tennessee
}

\author{
D. D. Goff
}

Date Issued-August 1991

\author{
Prepared by \\ Health and Safety Research Division \\ Oak Ridge National Laboratory \\ Prepared for \\ U.S. Department of Energy
}

Office of Environmental Restoration and Waste Management under budget and reporting code EW 20

OAK RIDGE NATIONAL LABORATORY

Oak Ridge, Tennessee 37831-6285 managed by

MARTIN MARIETTA ENERGY SYSTEMS, INC:

for the

U.S. DEPARTMENT OF ENERGY

under contract DE-AC05-84OR21400 


\section{Author Affiliation}

D. D. Goff is a Master's graduate of The University of Tennessee, Knoxville, whose research assistantship entailed work in the Health and Safety Research Divison at Oak Ridge National Laboratory, Martin Marietta Energy Systems, Inc. 


\section{CONTENTS}

Page

FIGURES $\ldots \ldots \ldots \ldots \ldots \ldots \ldots \ldots \ldots \ldots \ldots \ldots \ldots \ldots \ldots \ldots$

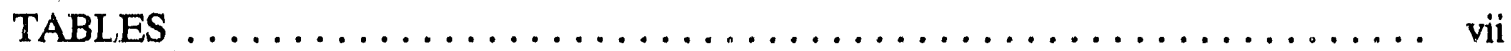

ACKNOWLEDGMENTS $\ldots \ldots \ldots \ldots \ldots \ldots \ldots \ldots \ldots \ldots \ldots \ldots \ldots \ldots \ldots \ldots \ldots$

EXECUTTVE SUMMARY $\ldots \ldots \ldots \ldots \ldots \ldots \ldots \ldots \ldots \ldots \ldots \ldots \ldots \ldots$

1. INTRODUCTION $: \ldots \ldots \ldots \ldots \ldots \ldots \ldots \ldots \ldots \ldots \ldots \ldots \ldots \ldots \ldots$

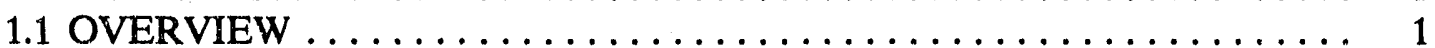

1.2 PROJECT RATIONALE $\ldots \ldots \ldots \ldots \ldots \ldots \ldots \ldots \ldots \ldots \ldots \ldots$

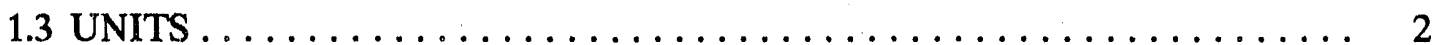

1.4 ORGANIZATION $\ldots \ldots \ldots \ldots \ldots \ldots \ldots \ldots \ldots \ldots \ldots \ldots \ldots \ldots$

2. REVIEW OF THE LITERATURE $\ldots \ldots \ldots \ldots \ldots \ldots \ldots \ldots \ldots \ldots \ldots$

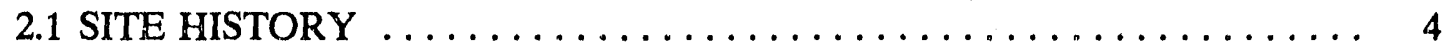

2.2 GEOLOGY AND HYDROLOGY $\ldots \ldots \ldots \ldots \ldots \ldots \ldots \ldots \ldots \ldots \ldots$

2.3 RADIONUCLIDE MIGRATION MECHANISMS $\ldots \ldots \ldots \ldots \ldots \ldots \ldots$

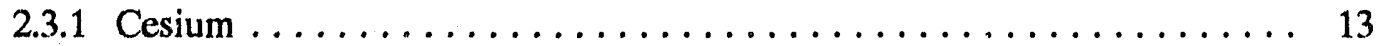

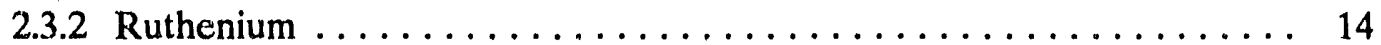

2.3.3 Strontium ........................ 14

2.4 SEEPAGE TRENCH OPERATION ................. 15

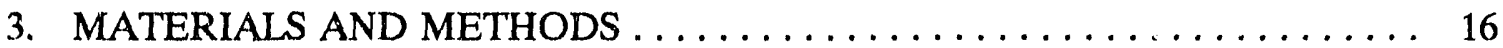

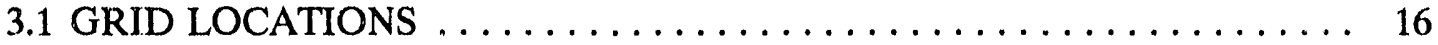

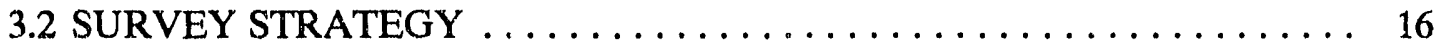

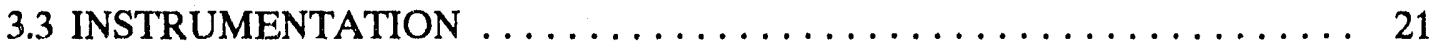

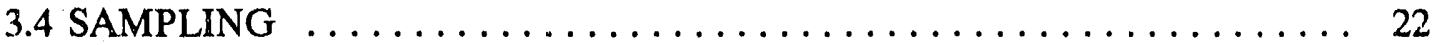

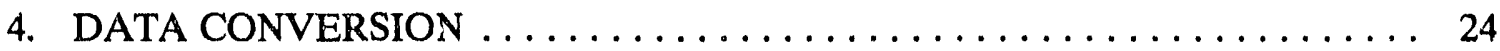

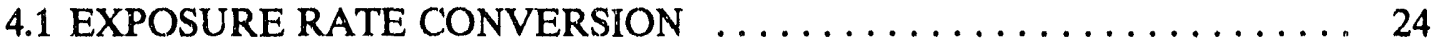

4.2 DISCUSSION OF MODEL SIGNIFICANCE .............. 28

4.3 BETA-GAMMA DOSE RATE CONVERSION $\ldots \ldots \ldots \ldots \ldots \ldots \ldots \ldots 32$

4.4 ALPHA ACTIVITY CONVERSION $\ldots \ldots \ldots \ldots \ldots \ldots \ldots \ldots \ldots \ldots . \ldots \ldots$

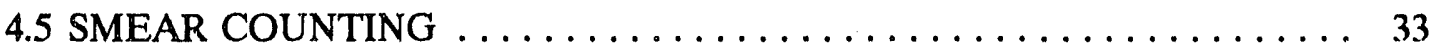

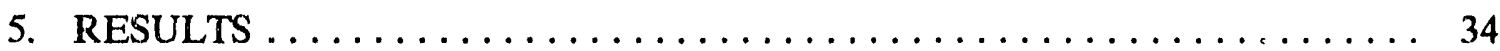

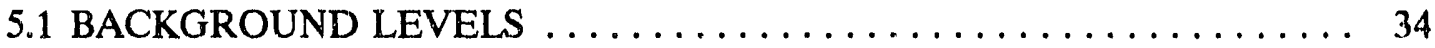

5.2 SURFACE GAMMA SCAN $\ldots \ldots \ldots \ldots \ldots \ldots \ldots \ldots \ldots \ldots \ldots \ldots \ldots$

5.3 BETA-GAMMA MEASUREMENTS . . . . . . . . . . . . . . . 37

5.4 ALPHA MEASUREMENTS $\ldots \ldots \ldots \ldots \ldots \ldots \ldots \ldots \ldots \ldots \ldots \ldots \ldots \ldots . \ldots \ldots . \ldots \ldots$

5.5 SOIL AND VEGETATION SAMPLE ANALYSES $\ldots \ldots \ldots \ldots \ldots \ldots \ldots \ldots . \ldots . \ldots . \ldots$

5.6 SMEAR ANALYSIS $\ldots \ldots \ldots \ldots \ldots \ldots \ldots \ldots \ldots \ldots \ldots \ldots \ldots \ldots$ 
6. CONCLUSIONS AND RECOMMENDATIONS $\ldots \ldots \ldots \ldots \ldots \ldots \ldots \ldots . \ldots 4$

6.1 CRITERIA ... . . . . . . . . . . . . . . . . . . . . . . 44

6.2 RECOMMENDATIONS FOR CORRECTIVE ACTIONS . . . . . . . . . 44

6.3 GENERAL OBSERVATIONS .................... 47

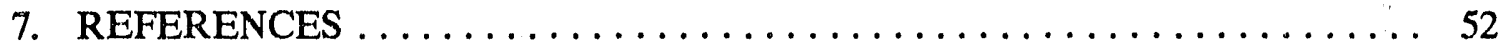

APPENDIX A. UNITS AND CONVERSIONS $\ldots \ldots \ldots \ldots \ldots \ldots \ldots \ldots \ldots$

APPENDIX B. SUMMARY OF STRONTIUM ANALYSIS $\ldots \ldots \ldots \ldots \ldots \ldots \ldots 1$

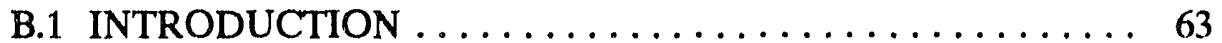

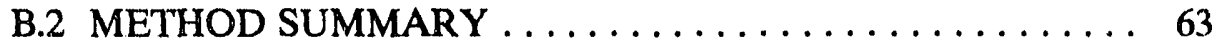

B.3 CALCULATIONS ..................... 64 


\section{FIGURES}

Figure

Page

1 Aerial view looking generally east at pits and trenches of WAG $7 \ldots \ldots$

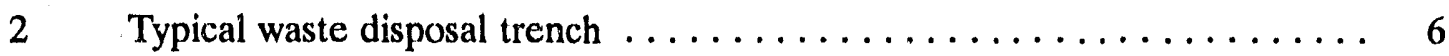

3 Construction of Trench 5 , spring $1960 \ldots \ldots \ldots \ldots \ldots \ldots \ldots$

$4 \quad$ View looking north along Trench 5 , summer $1990 \ldots \ldots \ldots \ldots \ldots$

$5 \quad$ View looking south along Trench 5 , summer $1990 \ldots \ldots \ldots \ldots$

6 Selected brass plaque affixed to HRE fuel wells, summer $1990 \ldots \ldots \ldots \ldots 12$

7 Background exposure rates of surveyed areas at Trench $5 \ldots \ldots \ldots \ldots$

$8 \quad$ Approximate regions of elevated surface exposure rates and sampling locations in surveyed areas at Trench $5 \ldots \ldots \ldots \ldots \ldots$

9 Regression statistics for unweighted scheme $\ldots \ldots \ldots \ldots \ldots \ldots \ldots \ldots$

$10 \quad$ Regression statistics for weighted scheme $\ldots \ldots \ldots \ldots \ldots \ldots \ldots \ldots$

11 Graph of exposure rate conversion data $\ldots \ldots \ldots \ldots \ldots \ldots \ldots \ldots$

12 Selected pipes found near T'rench 5 , summer $1990 \ldots \ldots \ldots \ldots \ldots$

13 Metal apparatus found near Trench 5 , summer $1990 \ldots \ldots \ldots \ldots$

14 Well at the northern end of Trench 5 exhibiting elevated exposure rates, summer $1990 \ldots \ldots \ldots \ldots \ldots \ldots \ldots \ldots \ldots . \ldots \ldots$

15 View from gravel road looking east at the valve area exhibiting elevated exposure rates, summer $1990 \ldots \ldots \ldots \ldots \ldots \ldots \ldots . \ldots . . .49$

16 Valve in $0+00 \mathrm{~L} 100$ grid block exhibiting elevated exposure rates,

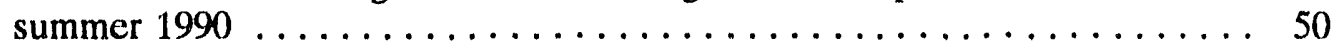




\section{TABLES}

Table

$\underline{\text { Page }}$

1 Isotopic inventory of Trench $5 \ldots \ldots \ldots \ldots \ldots \ldots \ldots \ldots \ldots \ldots$

2 Exposure rate data for conversion factor calculation at Trench $5 \ldots \ldots 25$

3 Exposure rates at grid intersections at Trench $5 \ldots \ldots \ldots \ldots \ldots$

$4 \quad$ Summary of pipe surveys at Trench $5 \ldots \ldots \ldots \ldots \ldots \ldots \ldots$

$5 \quad$ Concentrations of ${ }^{137} \mathrm{Cs}$ and ${ }^{60} \mathrm{Co}$ in soil samples from Trench $5 \ldots \ldots .40$

6 Summary of radiochemical analysis performed by the Analytical Chemistry Division $\ldots \ldots \ldots \ldots \ldots \ldots \ldots \ldots \ldots \ldots \ldots \ldots \ldots \ldots$

$7 \quad$ Analysis results of smears at Trench $5 \ldots \ldots \ldots \ldots \ldots \ldots$

A.1 Conversions and equivalent SI units for traditional units $\ldots \ldots \ldots \ldots \ldots 58$ 


\section{ACKNOWLEDGMENTS}

I would like to thank The University of Tennessee and Oak Ridge National Laboratory (ORNL) for their academic and financial support. The Health and Safety Research Division and the Environmental Restoration Program sponsored the work at ORNL. Dr. Richard Swaja was instrumental in providing me with the opportunity to perform this work for these ORNL organizations. I also thank the members of my thesis* committee: Drs. Peter Groer, Lawrence F. Miller, and James E. Turner.

In the course of performing the work presented here, a number of individuals assisted me in making its successful completion possible: John F. Allred, Romance F. Carrier, Robert L. Coleman, Ray D. Foley, Robert C. Gosslee, Richard A. Mathis, Vaughn P. Patania, Dennis E. Rice, Debbie A. Roberts, Rick E. Rodriguez, Doug A. Rose, R. B. Slaten, Tony R. Stewart, Mary S. Uziel, and Elaine A. Zheighami. One person in particular-Ms. Peggy F. Tiner-guided me through the project from beginning to end. To her I am deeply indebted. Special thanks, also, to Mr. John K. Williams for his unrelenting efforts.

The individuals at ORNL who read, critiqued, and helped to improve this report were T. W. Burwinkle, H. M. Butler, R. L. Coleman, L. S. Corrill, H. R. Gaddis, A. L. Harkey, L. Holder, Jr., L. D. Hyde, J. E. Nyquist, R. E. Swaja, P. F. Tiner, and J. K. Williams.

For all the support and succor during times of need, I thank my fellow graduate students in the Nuclear Engineering Department at The University of Tennessee, Knoxville, and especially Jeff A. Chapman for his patience and guidance.

\footnotetext{
*'I his work was originally published as a thesis in partial fulfillment of requirements for a master's degree in nuclear engineering at The University of Tennessee.
} 


\section{EXECUTIVE, SUMMARY}

A surface radiological investigation of areas encompassing Trench 5 on the Oak Ridge Reservation was conducted from May 1990 through November 1990. This survey was led by the author, assisted by various members of the Measurement Applications and Development Group of the Health and Safety Research Division of Oak Ridge National Laboratory in Oak Ridge, Tennessee. The purposes of this investigation were twofold. First, the presence, nature, and extent of any surface radiological contamination were explored. Second, based on the data gathered, interim corrective measures were recommended to limit human exposure to radioactivity and to minimize the environmental dispersion of radioactive contaminants.

Numerous surface areas having elevated exposure rates were identified in areas circumjacent to the trench. The asphalt cap covering the trench showed generally lower exposure rates, except for very high collimated radiation fields at vent openings in the asphalt. The primary soil contaminant was ${ }^{137} \mathrm{Cs}$. Strontium-90 was present in some vegetation near the trench, so it is probably present in the nearby soil as well.

Several areas were strewn with metal, rubber, and plastic pipe sections. Alpha, beta, and gamma contamination was discovered on the metal pipes; some of the beta contamination was removable.

Seven shallow wells that contain uranium and fission products in a nitric acid solution are located near the trench. Each of these wells appears to be wholly intact; no surface contamination was detected. 


\section{INTRODUCTION}

\subsection{OVERVIEW}

A surface radiological investigation of areas encompassing Trench 5 on the Oak Ridge Reservation (ORR) was conducted from May 1990 through November 1990. This survey was led by the author, assisted by various members of the Measurement Applications and Development (MAD) group of the Health and Safety Research Division (HASRD) of Oak Ridge National Laboratory (ORNL) in Oak Ridge, Tennessee.

The purpose of the investigation was to determine the presence, nature, and extent of surface radiological contamination at Trench 5, the Homogeneous Reactor Experiment fuel wells, and surrounding areas. Based on the data obiained in the field, interim corrective measures were recommended to limit human exposure to radioactivity and to minimize insult to the environment.

It should be stressed that this project was not intended to be a complete site characterization but rather to be a preliminary investigation into the potential contamination problem that might exist as a result of past operations at Trench 5. A more detailed study would be warranted if the preliminary investigation revealed a need to know more accurately and completely characterize the contamination conditions at the trench and surrounding area.

A more extensive characterization would require a more thorough systematic sampling scheme in which subsurface core samples would be needed to determine possible radionuclide migration. Gilbert (1987) outlines various sampling strategies and related statistical calculations that would apply to such a project. These increased efforts would demand a corresponding increase in funds, time, and manpower. No immediate need for such expenditures was noted at this particular site, and Gilbert's discussions are beyond the scope of this paper.

This project did, however, require the use of a variety of field and laboratory instruments and techniques. Detailed accounts of these instruments and techniques follow.

\subsection{PROJECT RATIONALE}

The U.S. Department of Encrgy (DOE) is required to be in full compliance with all federal and state regulations, including those regarding waste characterization and disposal. At ORNL the Remedial Action Program (RAP) was established "in response to this requirement ... to provide comprehensive management of areas where past and current ... waste management activities have resulted in residual contamination of facilities or the environment" (P. F. Tiner, HASRD, ORNL, personal communication to D. D. Goff, The University of Tennessee, Knoxville, April 1991). It should be noted that during the course of the project, RAP changed its name to Environmental Restoration Program (ERP). 
ERP efforts help ensure that hazardous and radioactive materials abandoned at inactive sites do not present a threat to the public or the environment. These efforts were motivated by the Comprehensive Environmental Response, Compensation, and Liability Act (CERCLA) and, in certain cases, the Resource Conservation and Recovery Act (RCRA). Sites falling under the jurisciction of the program at ORNL were identified and subdivided into more manageable units known as Waste Area Groupings (WAG). Each WAG contains facilities that share similar geological and hydrological characteristics. The WAGs are monitored regularly for possible migration of the materials sequestered there.

Even so, individual units within the WAGs must be cvaluated. As a part of their mission, the MAD group members perform some of these environmental assessments. Additionally, they work at various DOE sites under the auspices of many environmental programs. The work at Trench 5 was done for ERP.

\subsection{UNITS}

The International Commission on Radiation Units and Measurements (ICRU), in 1980, issued its Report 33: Radiation Quantities anc Units (ICRU 1980), which defined various terms and units applicable to radiation and radiation-induced events. Each of these definitions was based on the Systeme International (SI), or metric system of units. The report standardized which SI units, their derived units, and other units used in the field are considered appropriate.

To date, radiation-related quantities are expressed in the traditional system in many ORNL reports. Many of the instruments used to collect and analyze the data for this project use the older units as well. In all cases in this document, the ICRU-specified units are employed with the traditional units given parenthetically. The conversion constants for specific units are summarized in Table A.1 in Appendix A.

\subsection{ORGANIZATION}

Subsequent portions of this report present information concerning specific procedures at various stages of the project. The report is divided into six sections with accompanying appendixes.

Section 1 provides an overview and statement of the problem. A brief statement about the SI units used throughout the document appears here as well. Information regarding the mission of the MAD group and its activities also appears.

Section 2 contains a general site history, as accurately as it is known, followed by a brief look at geological aspects of waste disposal sites that affect their ability to perform adequately. A review of the transport mechanisms and geochemical characteristics of the radionuclides applicable to this project is presented. 
Section 3 outlines the equipment and techniques used to survey the site. Included are an explanation of the mapping system, an overview of the survey strategy, a description of instruments and their use, and sampling schemes used.

Section 4 deals with calibration factors for converting the various field measurements into useful, meaningful quantities. Details regarding the statistical correlation between scintillator count rate and exposure rate are explained.

Section 5 presents the results of the surveys and analyses conducted regarding Trench 5 . Field and in situ measurements along with laboratory analytical methods were exploited to reduce the data collected to a manageable size.

Section 6 contains the conclusions based on the results of the survey. Site-specific recomrnendations on possible corrective actions are proposed. 


\section{REVIEW OF THE LITERATURE}

\subsection{SITE HISTORY}

Fuel reprocessing operations, begun during the Manhattan Project, initiated the generation of intermediate-level liquid wastes (ILW) at ORNL. According to ORNL, ILW contained activities between 0.039 and $4.4 \mathrm{GBq} \mathrm{L}^{-1}\left(0.004\right.$ and $\left.5 \mathrm{Ci} \mathrm{gal}^{-1}\right)$ (Coobs and Gissel 1986).

The ILW at ORNL was generated by many different processes: radiochemistry laboratories; reactor fuel reprocessing systems; isotope production facilities for use in industrial, medical, and research applications; operation of nuclear research reactors; and decontamination efforts. Primary sources included the Chemical Separations Facility, the Oak Ridge Research Reactor, the Bulk Shielding Reactor, the High Flux lisotope Reactor, and various laboratory research facilities (Coobs and Gissel 1986).

Before construction of the pits and trenches encompassed by WAG 7, underground tanks were built to temporarily store the waste after recovery of uranium and plutonium. Most radioactive contaminants were precipitated in the tanks by adding caustic. The supernatants were processed variously. Until 1949, the liquids from the tanks were diluted with ORNL's low-level process waste and sent to settling basins and retention ponds before release to White Oak Creek. Stricter disposal requirements in 1949 initiated the use of an evaporator. The effluents were concentrated in the process, with the condensate transferred to the lowlevel waste system, and the concentrated waste stored in underground tanks. Starting in 1952 the liquid waste was sent to the newly constructed pits encompassed by the WAG 7 area (Coobs and Gissel 1986). These pits served as the major waste disposal facilities for the next few years but eventually could no longer meet the demands placed on them.

Trench 5 was constructed in May 1960 on a ridge seveıal hundred meters east of Seepage Pits 2,3, and 4 in WAG 7 to help satisfy the increasing waste disposal needs of ORNL. The trench was the first design of its kind: a long, narrow, covered trench as opposed to a roughly cylindrical, open pit. Figure 1 shows the general locations of the pits and trenches of WAG 7. Fi gure 2 illustrates the construction characteristics of a typical liquid waste disposal trench. Figure 3 depicts Trench 5 during its consiruction in 1960. The trench is shown in Figs. 4 and 5 as it looked during the summer of 1990 with its asphalt cap and vents visible. The large, white, dumpsterlike metal box depicted in Fig. 4 was a tumulous waste box put there by the facility manager in preparation to remove and properly store materials found near the trench.

Until the construction of Trench 5, previous facilities had exhibited operational problems. First, intense radiation fields at the edge of the open pits restricted personnel activities near them. The activity level of these fields ranged from 13 to $1032 \mu \mathrm{C} \mathrm{kg}^{-1} \mathrm{~h}^{-1}$ (50 to $4000 \mathrm{mR} \mathrm{h}^{-1}$ ). Trench 5 differed from other trenches in its construction by incorporating an earthen cover over the trench. The several feet of soil and rock attenuated the field sufficiently to allow operations on the surface. The cover also eliminated the need for protective netting such as that placed over the open pits to protect workers from falling in and to prevent waterfowl from alighting on the surface. 


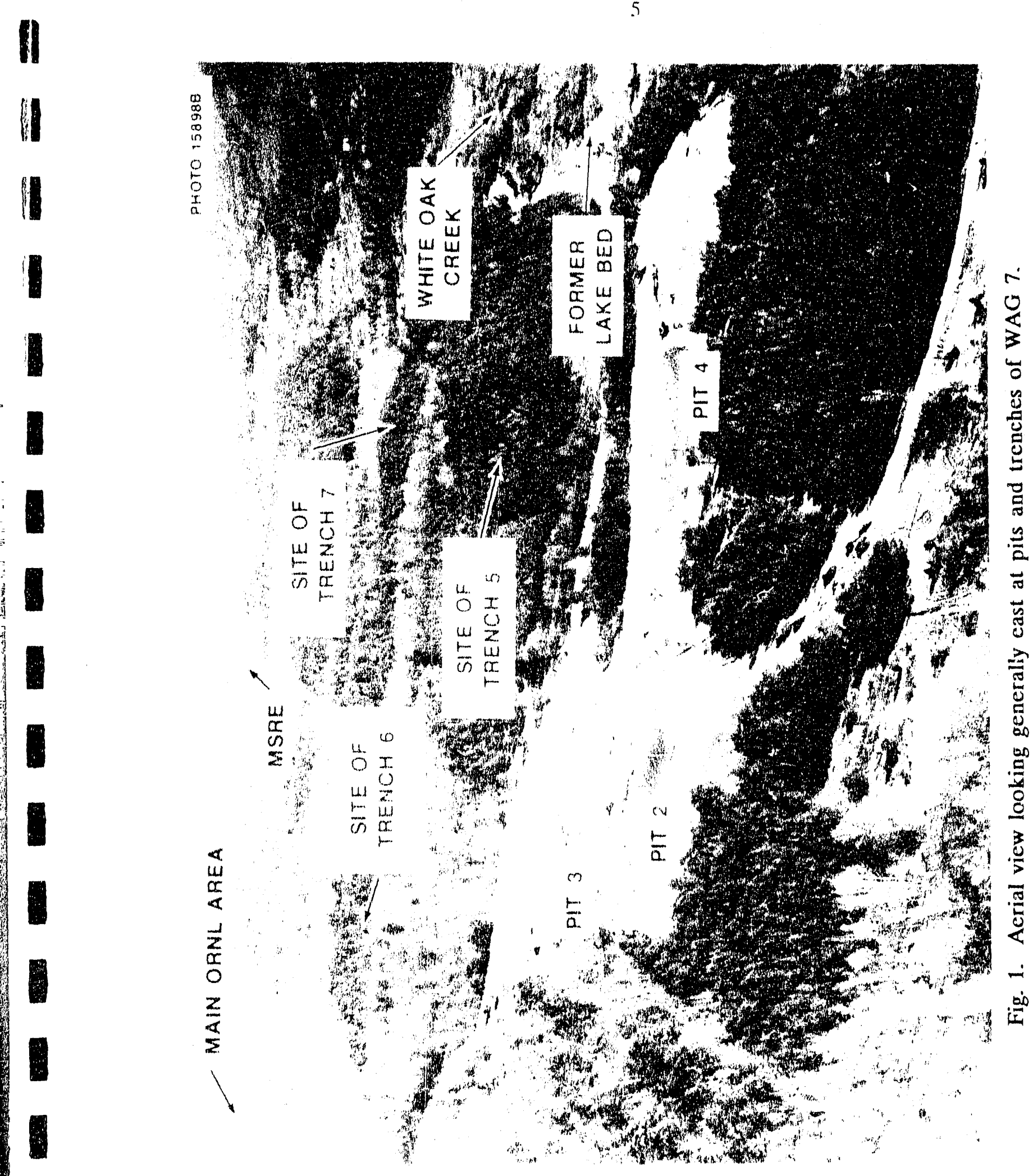




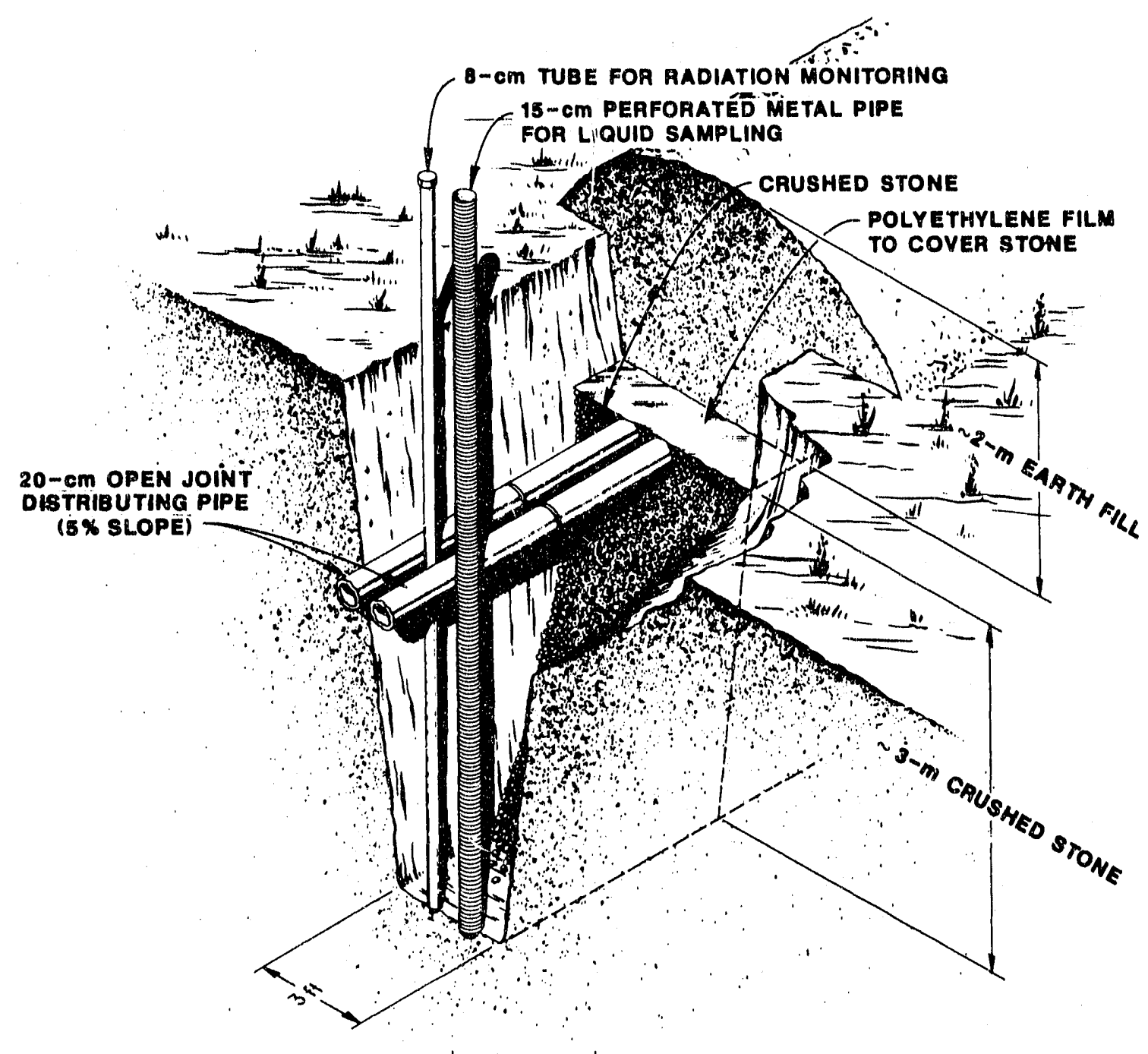

Fig. 2. Typical waste disposal trench. 

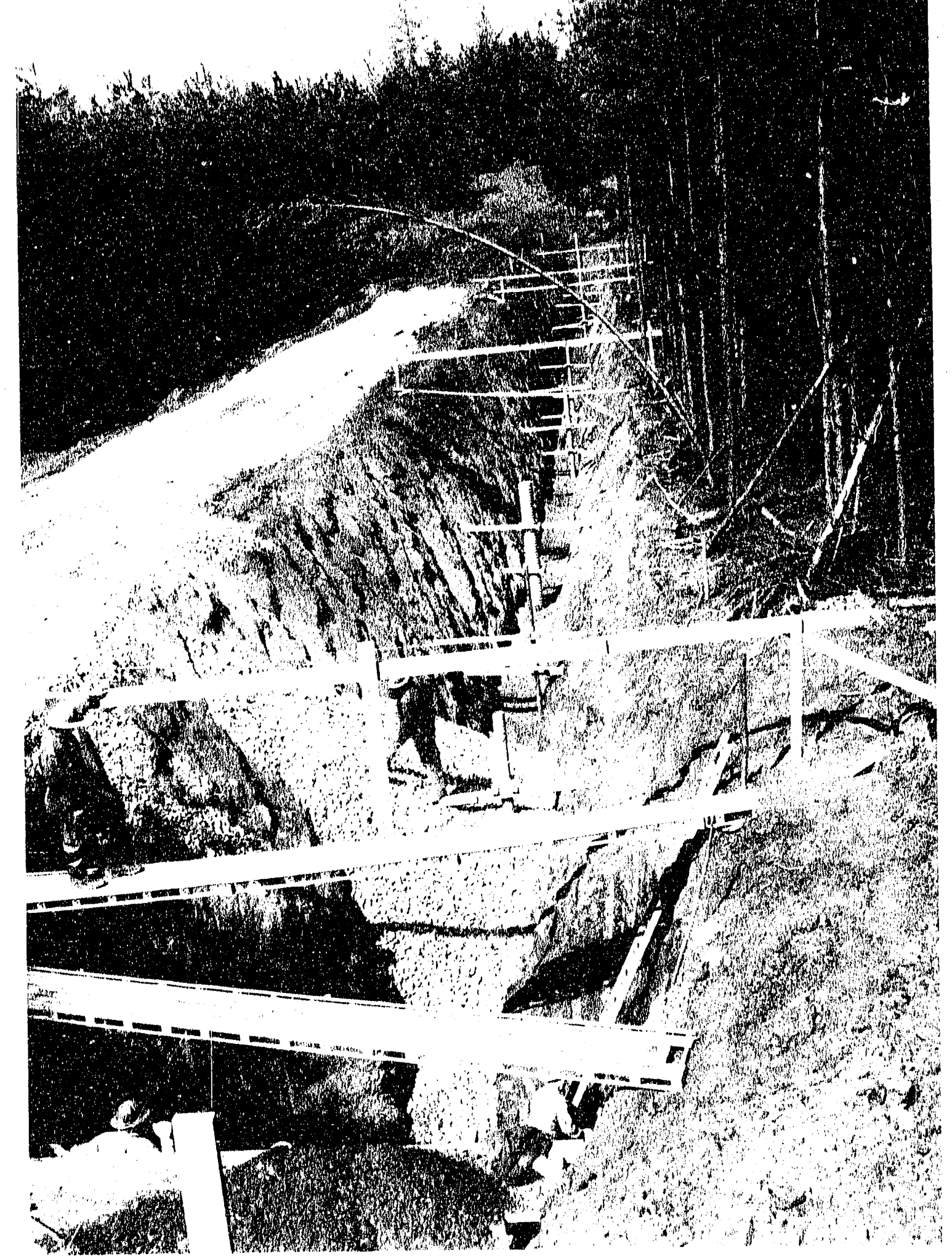

Fig. 3. Construction of Trench 5, spring 1960. 


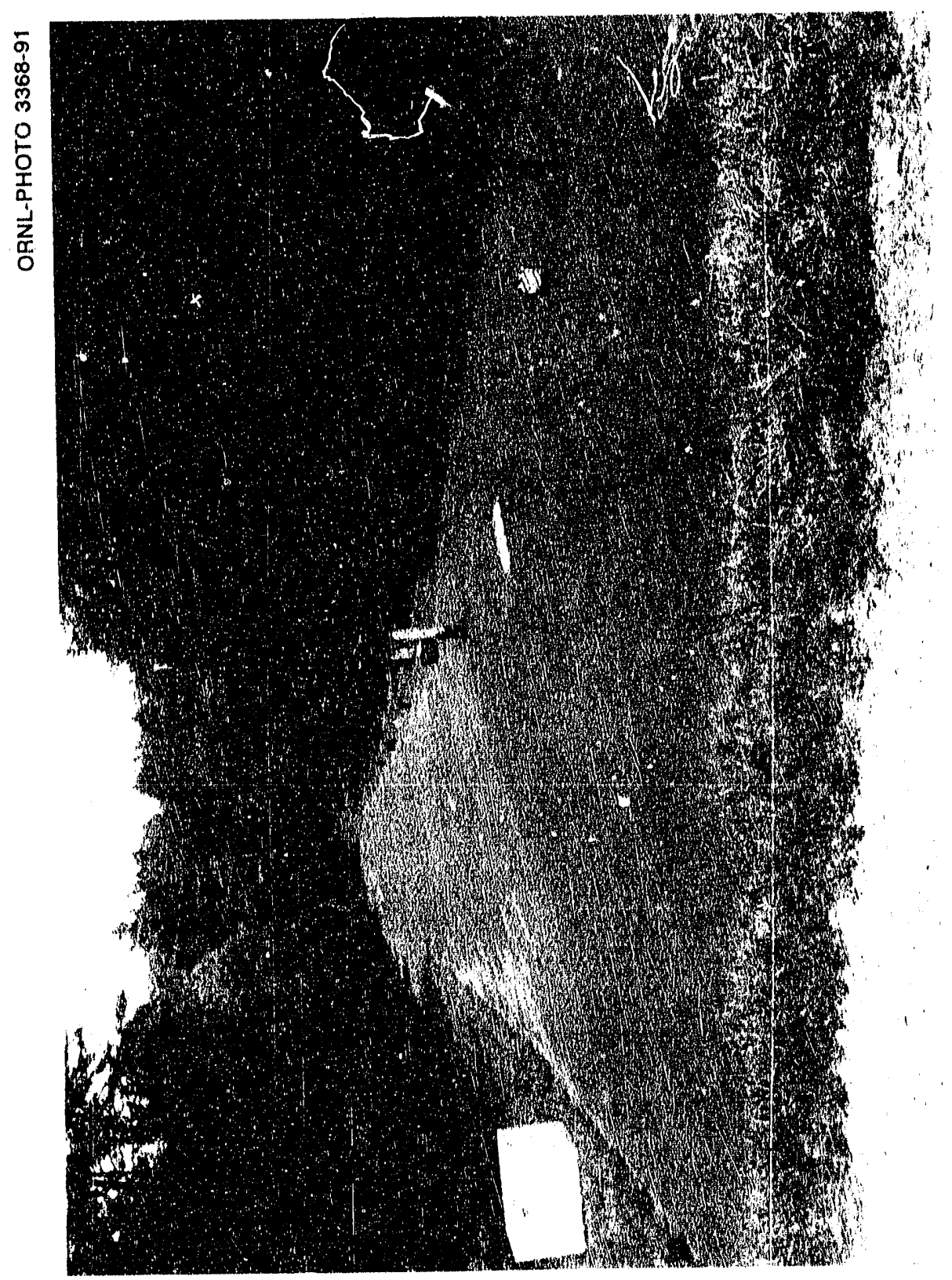

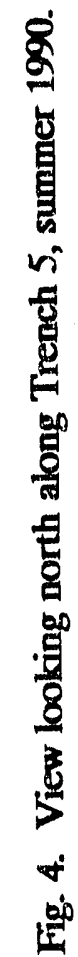

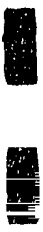
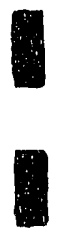

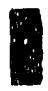

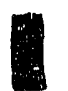

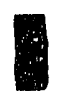

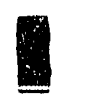




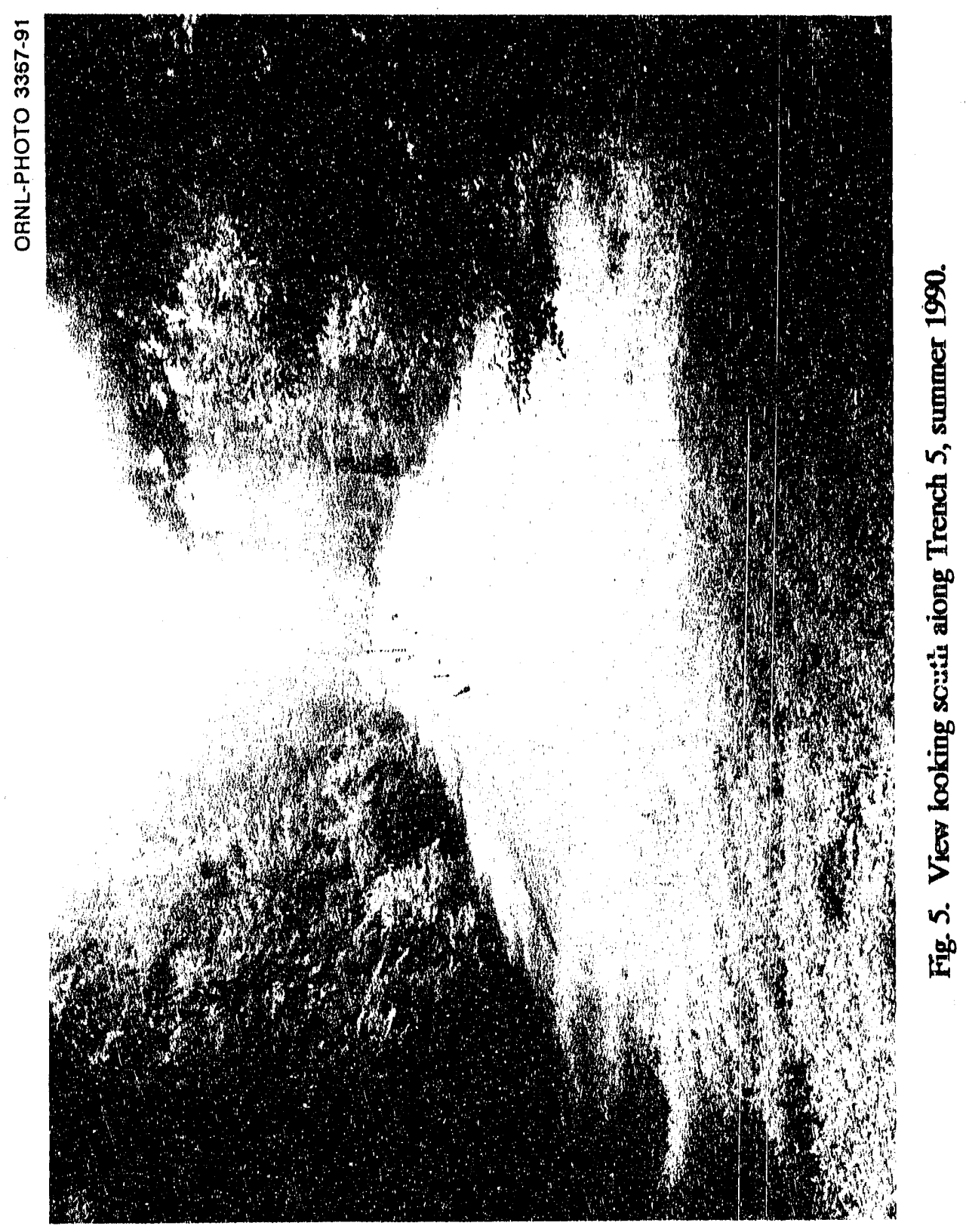


Second, in this region of the country, the ratio of annual precipitation to evaporation is roughly 2:1. Although summertime evaporative losses were desirable from a volume reduction standpoint, a covered trench would compensate by not accumulating nearly as much precipitation as an open pit. Negligible gains and losses from these mechanisms and known waste input rates make calculation of a much better estimate of the secpage possible.

Third, migration of ${ }^{106} \mathrm{Ru}$ in the seepage from the pits had been a major problem. A long, narrow trench with the unique geological orientation available to Trench 5 was expected to be much more desirable in terms of soil adsorption than the pits had been.

The trench was built approximately $92 \mathrm{~m}(300 \mathrm{ft})$ long, $1.2 \mathrm{~m} \mathrm{(4ft)}$ wide, and $4.6 \mathrm{~m}$ (15 ft) deep. On completion it was filled with $242 \times 10^{3} \mathrm{~L}\left(64 \times 10^{3} \mathrm{gal}\right)$ of water. To mitigate the ruthenium seepage problems encountered previously, the water in the trench was treated with $816 \mathrm{~kg}(1800 \mathrm{lb})$ of copper sulfate and $454 \mathrm{~kg}(1000 \mathrm{lb})$ of sodium sulfide. The water was then allowed to drain over the course of the next $19 \mathrm{~d}$. The maximum seepage rate occurred when the trench was most full and was found to be approximately $16.3 \times 10^{3} \mathrm{~L} \mathrm{~d}^{-1}$ (4300 gal d $\mathrm{d}^{-1}$ ). To prevent overflow into White Oak Creek, level control and recording devices were installed, rendering the trench ready for operation.

Waste was pumped into the trench for the first time in early July 1960. During the first months of operation, the trench received an average of $11.35 \times 10^{3} \mathrm{~L} \mathrm{~d}^{-1}\left(3000 \mathrm{gal} \mathrm{d}^{-1}\right)$. An isotopic inventory of the total wastes received by Trench 5 appears in Table 1 (Coobs and Gissel 1986). ORNL's waste generation consisted of about $28.4 \times 10^{3} \mathrm{~L} \mathrm{~d}^{-1}\left(7500 \mathrm{gal} \mathrm{d}^{-1}\right)$, requiring the use of the original pits. To remove the pits from service as soon as possible, other trenches similar in design to Trench 5 were planned and built in the vicinity (Fig. 2).

Surrounding the southern end of the trench are seven special disposal wells. Wells S-1 through S-7 were commissioned to receive residual fuel solution from the Homogeneous Reactor Experiment (HRE). Bored in 1964, each well is a cylindrical auger hole $0.3 \mathrm{~m}$ (12 in.) in diameter and $5 \mathrm{~m}(17 \mathrm{ft})$ deep and contains uranium of unknown enrichment and fission products in a $4 \mathrm{~N} \mathrm{H}_{2} \mathrm{SO}_{4}$ solution. Approximately $510 \mathrm{~L}$ of waste solution containing some $4 \mathrm{~kg}$ of uranium sulfate were disposed of at these sites. A brass plaque bearing the location and contents was affixed to each well (Fig. 6). A gravel road, part of improvements made to the Trench 5 area, was built over some of the wells. Regardless of their proximity to Trench 5, the HRE Fuel Wells are managed as a separate facility.

\subsection{GEOLOGY AND HYDROLOGY}

It is beyond the scope of this paper to address the complexities of geological and hydrological factors contributing to the characteristics of Trench 5. Codell and Duguid (1983) provide an introduction to groundwater transport modelling. These issues are dealt with herein on a superficial level.

Codell and Duguid (1983) explain that the "assessment of a low-level waste burial ground requires three types of models: (1) models to determine the portion of the radioactive source released if infiltrating water contacts the waste, (2) mathematical models in terms of measurable hydrologic parameters that predict the migration of radionuclides from the source 
Table 1. Isotopic inventory of Trench 5

\begin{tabular}{lcc}
\hline \multicolumn{1}{c}{ Isotope } & $\begin{array}{c}\text { Activity entering } \\
\text { Trench } 5 \\
(\mathrm{GBq})\end{array}$ & $\begin{array}{c}\text { Residual activity } \\
1 / 1 / 91 \\
(\mathrm{GBq})\end{array}$ \\
\hline & $1.1 \times 10^{5}$ & 4200 \\
Cobalt-60 & $3.6 \times 10^{6}$ & \\
$\begin{array}{l}\text { Strontium-89 } \\
\text { Strontium-90 }\end{array}$ & $1.9 \times 10^{5}$ & $2.0 \times 10^{6}$ \\
Ruthenium-106 & $7.7 \times 10^{6}$ & $<1.0 \times 10^{-3}$ \\
Cesium-137 & 1600 & $4.3 \times 10^{6}$ \\
$\begin{array}{l}\text { Other } \\
\text { (unspecified) }\end{array}$ & & Unknown \\
\hline
\end{tabular}




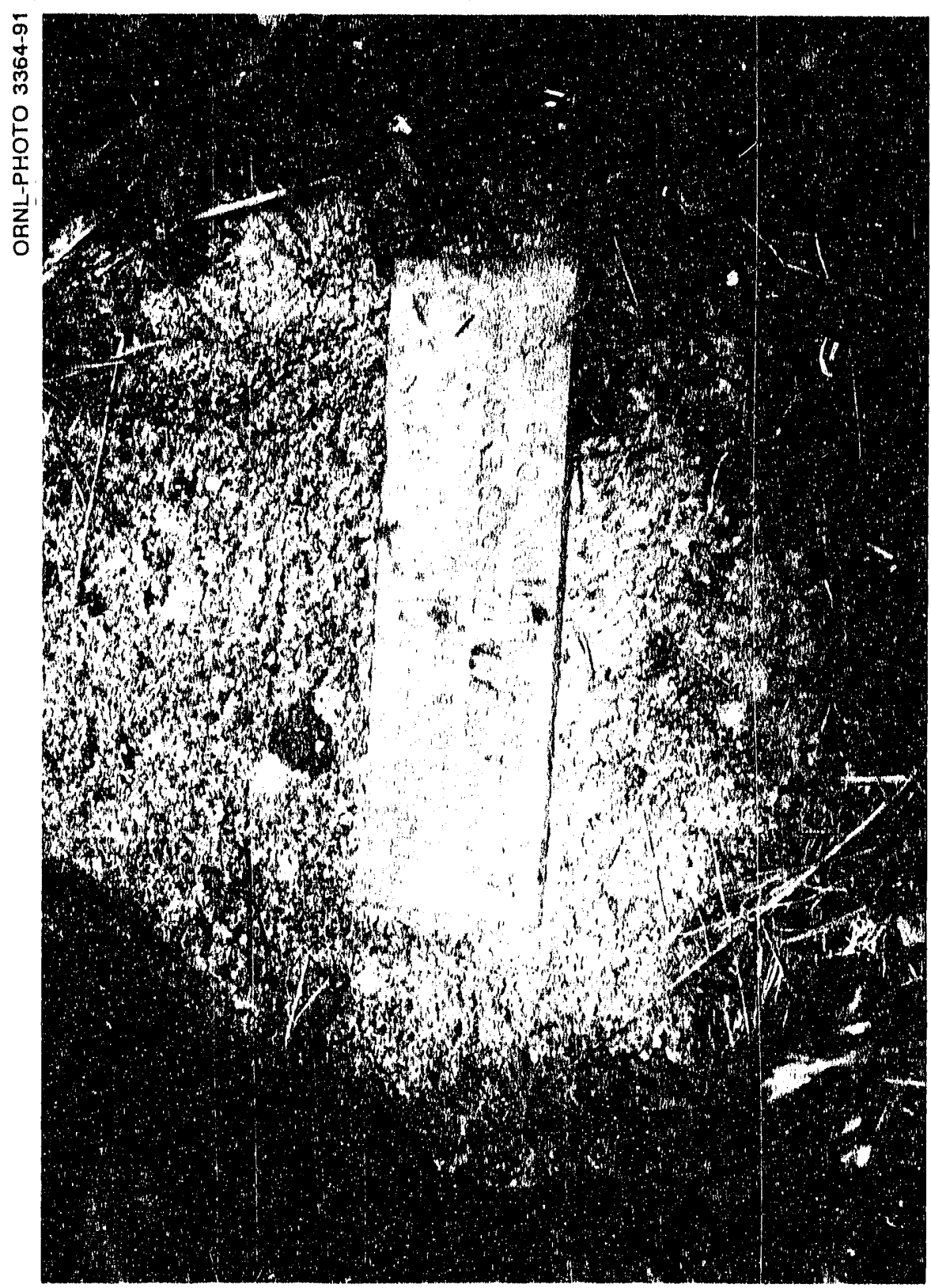

8 
to locations aceessible to the public, and (3) models determining the potential radiation dose using the radionuclide conecntrations that reach acesssible locations."

They note that "source term evaluation is highly sile-specific, depending on such lactors as the chemistry of the waste, the host rock, and the groundwater. Also, interaction between natural and man-made components ean play an important role in defining release mechanisms" (Codell and Duguid 1983).

\subsection{RADIONUCLIDE MIGRATION MECHANISMS}

This section considers migration of radioactive chemical species from the seepage trench. When the trench was in operation and for a period of time afterwards, all the nuclides present represented a potential hazard to personnel and the environment. The ruthenium placed in the trench during its operation has undergone sufficient radioactive decay to render the remaining activity insignificant. Thus, it is no longer a radiological hazard. For this discussion, however, ruthenium will be considered in addition to cesium and strontium.

Lomenick et al. (1967) studied radionuclide hehavior at the waste secpage pits near Trench 5. They found that, during operations at the pits, continuous use kept the water table artificially high, allowing groundwater to leach out some of the activity in the pits. The pits were maintained at a highly basic $\mathrm{pH}$, thereby minimizing the mobility of the nuclicles. After cessation of operations, downward percoletion through the asphalt caps resulted in neutralization of the basic environment. The asphalt caps, though, allow only limited downward flow through the pits such that the water currently in the pits should drain down slowly, returning the water table to its normal level. Because the normal groundwater level is several feet below the level of the pits, the waste-laden sludges are isolated from the leaching action of the subsurface water.

\subsubsection{Cesium}

The principal mode of essium production is the nuclear lission of uranium. Isotopes occurring that have significant hall-lives include ${ }^{134} \mathrm{Cs},{ }^{135} \mathrm{Cs}$, and ${ }^{137} \mathrm{Cs}$. Although the other isotopes are probably present in discounted quantities, only ${ }^{137} \mathrm{Cs}$ was mentioned in the operational reports of the trench.

Cesium's chemistry is typical of its alkali metal group. The majority of cesium compounds are highly soluble in water, and the cesium cation is monovalent (Onishi et al. 1981). Bacs and Mesmer (1976) concluded that in a high.pH environment, cesium cations may associate with abundant $\mathrm{OH}^{-}$ions. The extent of such complexing is difficult to determine. According to Charlot (1957), cesium very rarely forms soluble complexes. Testing at underground nuclear detonation siles revealed that $1.5 \%$ of the ecsium appeared as an elemertal colloid, and the rest was ionic and possibly adsorbed by other colloidal species (Onishi et al. 1981).

Field studies at White Oak Creek near ORNL revealed that illite in the sediment has a high affinity for cesium and, in fact, controls the sorption of eesium (Jenne and Wahlberg 1968; Carrigan et al. 1967; Carrigan 1968; Carrigan 1969; Lammers 1968; Lomenick and Tamura 1965; Pickering et al. 1965; Pickering et al. 1966; and Pickering 1970). The cesium tends to remain bound with these sediments under most environmental conditions, although 
leaching with strong acid removed the cesium in significant quantitics. Percolation of rainwater through the sediment had essentially no effect on cesium mobility (Onishi et al. 1981).

Lomenick et al. (1967) found that the cesium tended to remain in the seepage pits fixed to the clays and precipitate sludges along the bottom. Core samples revealed that the cesium concentrations were "reduced more than a million timos from the peak concentration in the sludge to the partially weathered shale about $0.5 \mathrm{~m}$ [SI conversion added] below the pit bottom."

In general, the primary geologic interaction is expected to be ion exchange as a result of its cationic form in solution and its aversion to colloids. Because ion exchange reactions tend to occur quickly, steady-state sorption is achieved rapidly (within several hours). Additionally, such sorption occurs preferentially to illitic minerals (Onishi et al. 1981).

\subsubsection{Ruthenium}

Ruthenium is also a fission product of uranium. The only isotopes persistent enough to be of concern from the vicwpoint of waste management are ${ }^{103} \mathrm{Ru}$ and ${ }^{106} \mathrm{Ru}$ (Onishi et al. 1981). Even though only the ${ }^{106} \mathrm{Ru}$ was quantified in the records, more than likely both isotopes are present.

Ruthenium exhibits several oxidation states in aqueous solutions and is known to form a variety of unique complexes with many different species. The chemistry of ruthenium is quite complicated and depends on the reduction-oxidation characteristics, $\mathrm{pH}$, and history of the solution (Onishi et al. 1981). However, in an alkaline environment ruthenium will form an insoluble hydrated dioxide.

In their field studies at White Oak Cicek, Jenne and Wahlberg (1968) noted that ruthenium was not sorbed to the sedim/nt like cesium. Onishi et al. (1981) summarized by concluding that the "fate of rutheniury in the environment is very dependent on the source .... Without knowledge of the ruthenium speciation it would be difficult to predict rutheniums [sic] migration poteutial."

\subsection{Strontium}

Strontium is also a major product resulting from nuclear fission, with ${ }^{90} \mathrm{Sr}$ being the only persistent concern from a waste management standpoint. Strontium-90 is found in transient equilibrium with its daughter ${ }^{\text {"N }} \mathrm{Y}$.

The concentration of naturally occurring strontium is usually much higher than the concentration of any waste solutions that may contact it (Vinogradov 1959). Strontium occurs naturally in shale and limestone in sizable concentrations, substituting for the calcium in those minerals (Onishi et al. 1981).

Strontium tends to stay in its principal cationic valence state in solution, eschewing colloidal suspensions and complexes with other available species (Izrael and Rovinsky 1970). In an acidic environment strontium and its common salts are highly soluble and, thus, highly mobile. However, in a basic environment strontium carbonate is stable and will contain almost 
all the strontlum activity. Under these conditions complexing of the strontium is practically nonexistent, and as a result, its mobility is severely curtailed. Strontium adsorption tends to depend on calcium and magnesium concentrations and uitually reaches equilibrium in a period of days (Onishi et al. 1981).

Extensive field studies were carried out at White Oak Creek, Tennessee, near the Oak Ridge Reservation. Jenne and Wahlberg (1968) determined that strontium releases quickly precipitated as carbonales.

Lomenick et al. (1967) found that most of the strontium remaining in the seepage pits was integrated with the illitic clays and the calcium carbonate in the shale. Vertical strontium concentrations in soil generally are associated with cesium contamination; many orders of magnitude reduction in the several centimeters beneath the bottom. They measured strontium's movement rate as $0.24 \mathrm{~m}$ per year.

\subsection{SEEPAGE TRENCH OPERATION}

The actual operation of a secpage trench relics on the physical and chemical interactions between the wastes, the soils and materials making up the trench, and the chemical treatments added to the trench prior to its operation. Quite simply, waste solutions containing radionuclides suspended, complexed, and dissolved in water are introduced into the trench. As the liquids make their way down to the water table below, they must filter through the trench ard subsurfare soils.

Cesium, as described above, is readily adsorbed by the illitic clays and sediments of the alkali treated trench. As long as the soil matrix stays intact, with no crosion or acidic leaching, then the cesium activity will be fixed in it to a large extent.

Ruthenium, in the alkaline trench, will precipitate out as a hydrated oxide. Ruthenium dioxide then remains in the soil matrix and has very little mobility, behaving as cesium does.

In a manner similar to ruthenium, strontium will precipitate out of a highly basic solution as a carbonate. Because strontium carbonate and chemically similar calcium carbonate are already immobile components of the shale, the strontium activity will be retained by the trench in the shale and sorbed onto the illite.

With long-term management (about 300 years or ten hall-lives), the radioactive compounds will remain associated with materials in the trench. There, the wastes can undergo radioactive decay with minimal risk to off-site personnel and minimil insult to the environment. 


\section{MATERIALS AND METHODS}

\subsection{GRID LOCATIONS}

For convenience in obtaining and reporting measurements, the trench and surrounding areas were divided into 15-m (50-ft) grid blocks as shown in Figs. 7 and 8 . Any location in the grid can be established by two coordinates. The first coordinate designates 100 - ft distances from the zero point plus two digits representing an additional number of feet. The second coordinate identifies distance in feet to the right or left of the baseline (BL). The grid blocks are identified by the two lines bounding the southern and western sides of the grid; that is, each block is designated according to the grid lines intersecting at its southwestern corner.

It should be noted that directions (e.g., north and south) used in referring to the grid are grid-specific. Grid north is parallel to the BL and toward increasing numbers, and the remaining compass points derive from it. Additionally, ORNL maintains its own coordinate system as shown in Figs. 7 and 8. For purposes of absolute orientation, ORNL north deviates only slightly from true north.

\subsection{SURVEY STK ATELY}

The scope of this project was limited to a preliminary investigation of radiation levels and contamination at the site. To that end, MAD procedures developed to ensure uniformity in conducting the surveys (Myrick et al. 1987) were followed.

Before gridding the site, a walkover was performed, which consisted of going to the site, observing where the scans would take place, and noting the potential problems. At Trench 5 all areas within the planned boundaries of the gamma scan were accessible, though some areas were fairly heavily forested. When the presence of several unexpected items was noted-pieces of rubber, plastic, and metal piping strewn about along the treelines near the trench-historical information about the site was songht (P. F. Tiner, HASRD, ORNL, personal communication to D. D. Goff, The University of Tennessee, Knoxville, July 1990). Specific nuclides to be expected were noted, and means to deteet them were planned. Next, the site was divided into smaller, more manageable tracts, as described in Sect. 3.1, so that accurate locations of the details might be obtained (see Figs. 7 and 8). Then the gamma scan was undertaken. This process consisted of taking many scintillator count rate measurements, which were later converted to exposure rates. Gamma scan data included

- count rates recorded at each grid point at the ground surface and at $1 \mathrm{~m}$ above the surface and

- area-averaged count rates over all of the g!jid blocks.

In addition to the gridded areas, the up-gradientslope from the north side of the trench was intermittently scanned for gamma activity; a waste transfer pipe existed in the region during portions of the trench's operation.

During this phase of the survey, beta-gamma and alpha spot-check measurements were made of selected areas suspected of possible beta and alpha contamination, which would be missed by the gamma scan. The selected areas consisted of trees near the trench; the metal 

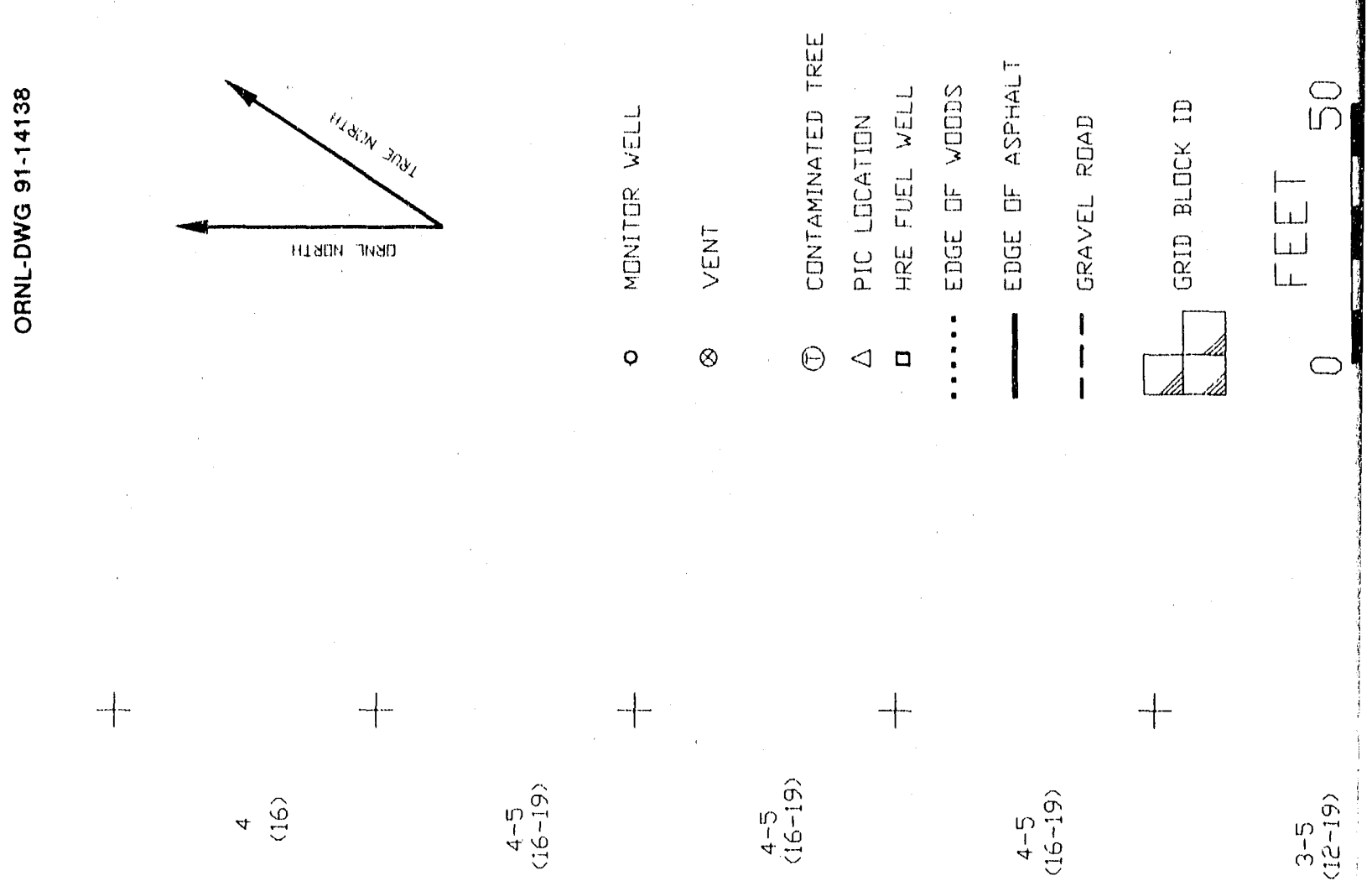

$+$

$+$

$+$
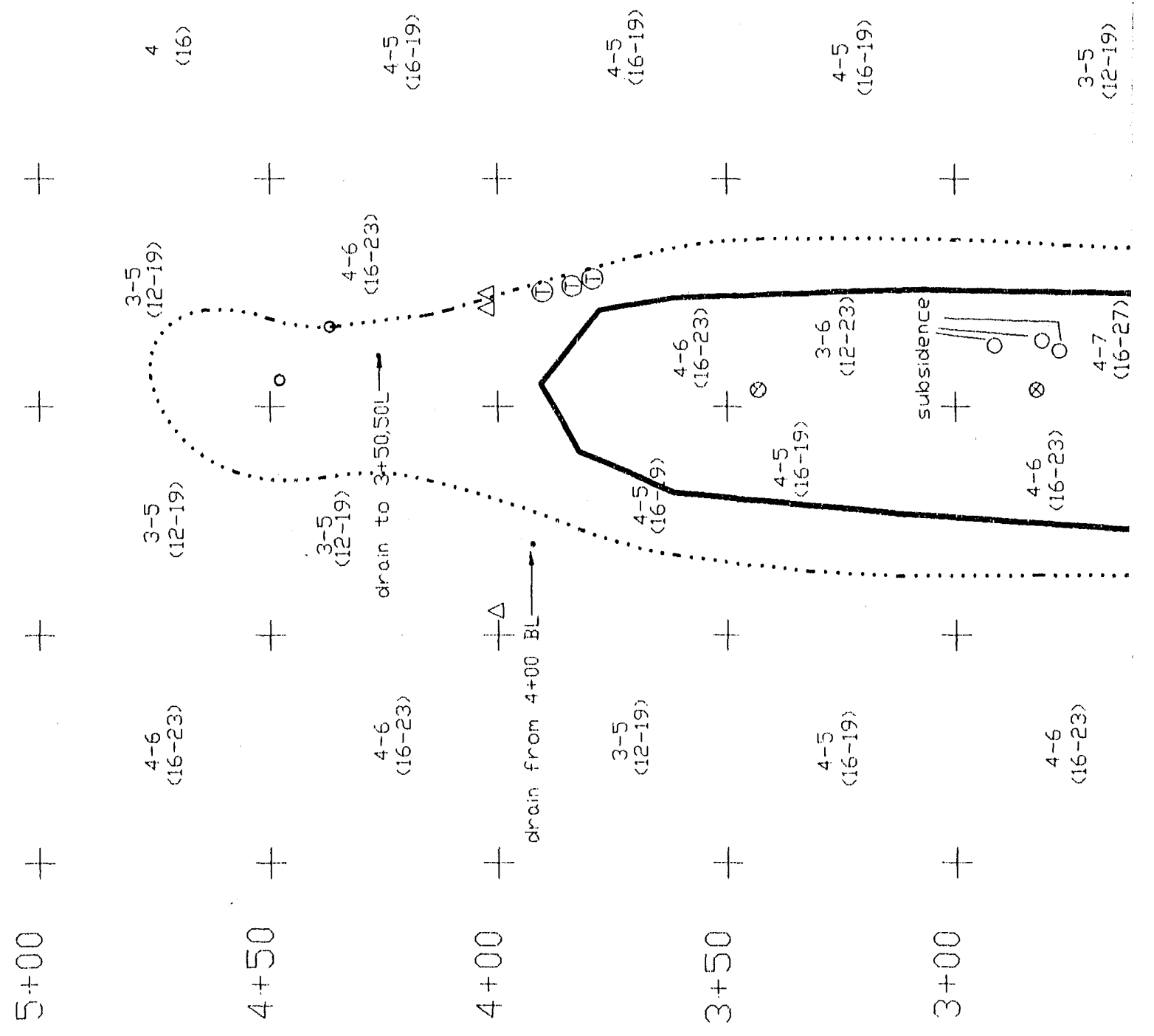


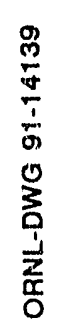

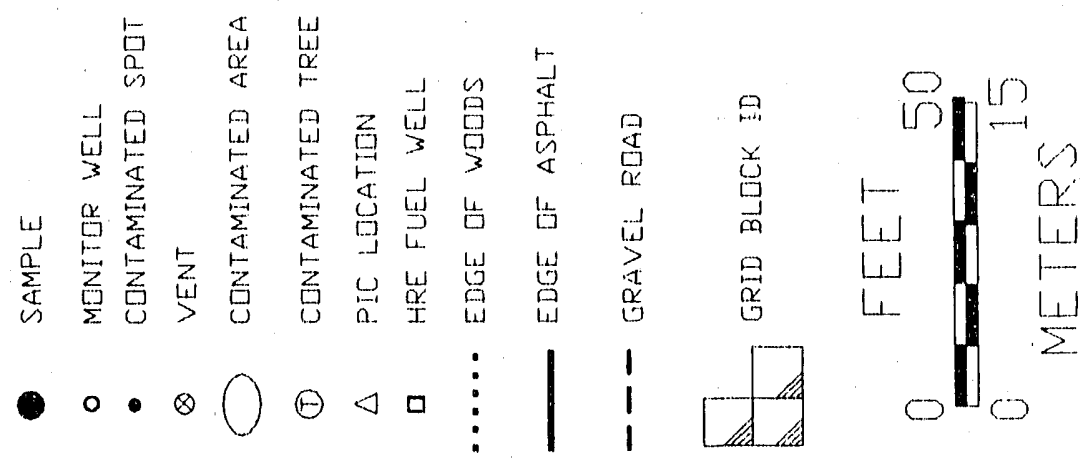

$+$

$+$

$-1$

$+$

$+$

تี $\widehat{\vec{\omega}} 0$

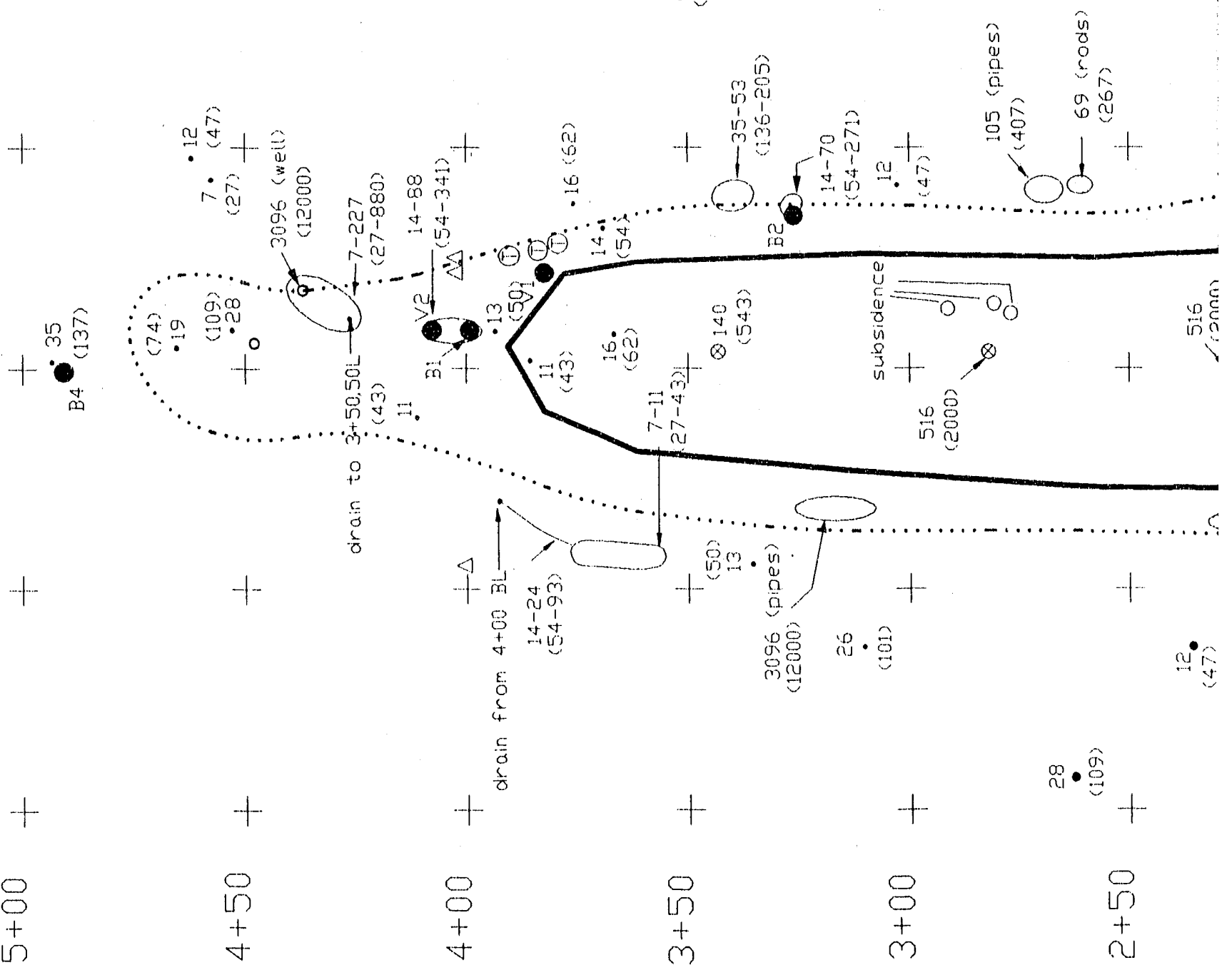


the trench; and other apparatus discovered during the course of the investigation. These areas were easily and quickly checked.

Later, soil sampling locations were chosen and samples taken. Several items suspected of bearing removable contamination were smeared, and the smears were subsequently counted and cataloged. The soil samples were also counted and cataloged after processing.

Completed survey maps showing background readings, areas of local contamination or radiation, etc., were submisted for digitization. Photographs of items of interest were taken at the site.

When all the information had been compiled, it was then necessary to organize it for inclusion in this document. Field measurements were converted to meaningful quantities.

\subsection{INSTRUMENTATION}

For the surface survey, 1.25 - by 1.5 -in. NaI(Tl) scintillation probes connected to Victoreen Model 490 Thyac III ratemeters were used to detect gamma activity. Because these instruments have energy-dependent responses, measurements made with them must be converted to exposure rates. Several measurements were taken with a Reuter-Stokes Environmental Radiation Monitor Model RSS-111. This device is a pressurized ionization chaniter (PIC). The energy-independent PIC exposure rate readings can be used to normalize the scintillator data to an exposure rate. In cases in which the gamma fields saturated the scintillators $\left(800 \times 11^{3} \mathrm{cpm}\right)$, a portable ionization chamber was used. This instrument was an ORNL Cutic Pic Mark V.

Beta-gamma radiation levels were measured by using a portable Eberline HP-260 pancake probe connected to a Bicron Analyst scaler/ratemeter. In cases in which the betagamma fields saturated the pancake detectors, a side window Geiger-Mueller (GM) tube connected to an Eberline Instruments E-120 ratemeter was used.

Alpha radiation levels were measured with an ORNL Q-2101 "beer mug" type ZnS scintillator probe connected to a Bicron Analyst scaler/ratemeter. It should be noted that some field surveys were conducted under somewhat moist conditions on nonplanar surfaces. However, all alpha spot-check measurements were performed under dry conditions on cylindrical pipes whose surfaces allowed contact with only a portion of the detector's active area. The geometry-induced air gaps between the contaminated surface and the detector would be expected to sharply attenuate alpha radiation and, to a lesser extent, beta radiation.

It should be noted that all measurements and quantities obtained in the field are gross counts. No attempt to generally quantify and subtract background counts or count rates was possible. For example, when relerring to scintillator count rate, kepm (thousands of counts per minute), refers to thousands of gross counts per minute.

In accordance with MAD standard practice (Davis and Gupton 1969), each instrument was checked daily to verify its calibration and good working order. Each irstrument was used to count an appropriate check source, and the resulting count was compared with expected 
values and acceptable fluctuations. Instruments that failed to conform to these standards were not used and were brought to the attention of the instrument manager.

Instrumelits other than those used in the field were employed for counting samples and smears. Soil samples were counted on any of five high-purity germanium (HPGe) spectroscopy systems in MAD's Gamma Spectroscopy Laboratory (GSL). These included a Tennelec Model CPVDS30-46190 with a crystal size of 64-mm diameter by 63-mm length, an Ortec Model GEM-20190-S with a crystal size of 55-mm diameter by $48-\mathrm{mm}$ length, and an Ortec Model GEM-30190-S with a crystal size of 58-mm diameter by $63-\mathrm{mm}$ length. These instruments were amplified by either an Ortec Model 571 or 572 spectroscopy-grade amplifier using digital stabilization. The signal was then acquired and analyzed by a Nuclear Data 9900 MicroVax and its accompanying spectral analysis software.

Smears were counted by using two systems. Alpha counting was done at the GSL with a Ludlum Model 43-10 ZnS detector coupled to a Ludlum Model 2000 scaler. Beta-gamma counting was done at ORNL's Dosimetry Applications Research facility. Instrumentation consisted of a plastic scintillator detector of unkriown manufacture whose signal was fed to a Ludlum Model 2001 scaler/ratemeter. Once again, the operational characteristics of these devices were monitored regularly by ORNL staff. Each was maintained in calibration and checked before use.

Vegetation and soil samples not analyzed by MAD staff were counted on a gas-flow proportional counter.

\subsection{SAMPLING}

To complete the project, some soil and vegetation samples were removed from the site for counting. Two types of samples were laken from various locations. Systematic samples were taken at selected points in the grid and were used for determining background activity levels. Biased samples were taken from points suspected to be contaminated.

On removal from the site, the samples were stored in a locked cabinet for later processing. Each sample was entered into the MAD computer inventory and tracking system. The samples remained in storage until they could be processed.

Sample processing comprised drying, grinding, and bottling the samples. Each sample was removed from the bag in which it had been stored and was placed in an ordinary aluminum baking dish. Samples were then placed in an oven and maintained at $110^{\circ} \mathrm{C}$ for $24 \mathrm{~h}$. This process drives off the water and any volatile organic compounds that may be present in the soil. These substances can lead to internal attenuation, or self-shielding, of a sample. Such a phenomenon will skew the counting results.

After drying, the samples were homogenized in a grinder, which eliminates lumps of soil, rock, or vegetable matter in the samples and leaves each sample in the form of a fine, homogeneous powder. Failure to homogenize a sample will lead to inconsistent geometries during analysis, thus invalidating the counting efficiencies. Care must be taken to clean the grinder throughly between each sample to avoid cross-contamination of the samples. 
Each ground sample was then bottled. Because of counting geometry requirements, each sample was loaded into $1220 \mathrm{~mL}$ polyethylene scintillation vials, each vial receiving approximately the same amount of sample. A bar code identification sticker, generated by the inventory and tracking system, was alfixed to each vial so that the samples can be quickly and accurately cataloged when they are counted. Finally, each group of vials was weighed, using an identical, empty set of vials as a tare so that the weight of the sample was known precisely. The weight is used during counting to quantify the specific activity of each sample.

At this point, the progress through the procedure was logged into the computer inventory and tracking system. The samples were returned to the locked cabinct and queued for spectrometric analysis.

The samples were eventually counted at MAD's GSL. The biased samples were counted for 0.5 to $4 \mathrm{~h}$, depending on the activity in the sample. The systematic samples were counted for $15 \mathrm{~h}$.

Some environmental samples were submitted to ORNL's Analytical Chemistry Division for strontium analysis. These processes were carricd out in accordance with U.S. Environmental Protection Agency (EPA) Method 905.0 (Prescribed Procedures for Measurement of Radioactivity in Drinking Water). A summary of these procedures is included as Appendix B.

The two vegetation samples were first ashed in a mulfle furnace and then dissolved in nitric acid. The soil sample was leached with nitric acid. Then these solutions were treated as EPA Method 905.0 stipulates. The samples were eventually counted in a gas-flow proportional counter. The results from this analysis appear in Sect. 5.5. 


\section{DATA CONVERSION}

\subsection{EXPOSURE RATE CONVERSION}

As was stated previously, the scintillation measurements had to be converted to exposure rates. The determination of the conversion factor from scintillator count rate to exposure rate was made by recording measurements in the field of these two quantities at several points. The scintillator count rate is a gross count rate.

The scintillometer used to detect gamma radiation levels was from the MAD instrument cache and was not exclusively used during the gamma survey. Exposure rate data were gathered by using a PIC the output of which was fed to an ORNL custom variable integrator; together, these two devices accurately measured an exposure rate integrated over a sclected time. All PIC data were compiled by using a 9()-sec integration time.

The locations where PIC measurements were taken are shown in Fig. 8. First, an integrated measurement of the exposure rate was made with the PIC. Then a measurement using the scintillator was recorded at the same spot. These data pairs were then used in a statistical regression. Table 2 contains these data as well as the cxposure rates expressed in SI units.

It is common practice to assume that the relationship between exposure rate and scintillator count rate is linear. For the ranges of values encountered at the trench, this assumption is generally true, as the data show. Equation (1) shows this relationship.

$$
y=\beta_{0}+\beta_{1} x+\varepsilon,
$$

where

$$
\begin{aligned}
y & =\text { exposure rate }\left(\mathrm{nC} \mathrm{kg}^{-1} \mathrm{~h}^{-1}\right), \\
\beta_{0} & =\text { intercept }\left(\mathrm{nC} \mathrm{kg-1} \mathrm{h}^{-1}\right), \\
\beta_{1} & =\text { slope }\left(\mathrm{nC} \mathrm{kg} \mathrm{k}^{-1} \mathrm{~h}^{-1} \mathrm{kcm}^{-1}\right), \\
x & =\text { scintillator count rate }(\mathrm{kcpm}), \\
\epsilon & =\text { statistical error }\left(\mathrm{nC} \mathrm{kg}^{-1} \mathrm{~h}^{-1}\right) .
\end{aligned}
$$

A least-squares linear regression gives unbiased estimates for the unknown values of $\beta$. These estimates are represented by $b$ with corresponding subscripts.

$$
y=b_{0}+b_{1} x
$$


Table 2. Exposure rate data for conversion factor calculation at Trench 5

\begin{tabular}{|c|c|c|c|}
\hline \multirow{2}{*}{$\begin{array}{l}\text { Approximate } \\
\text { location }\end{array}$} & \multirow{2}{*}{$\begin{array}{c}\text { Scintillator } \\
\text { count rate } \\
(\mathrm{kcpm})\end{array}$} & \multicolumn{2}{|c|}{ PIC exposure rate } \\
\hline & & $\left(\mu R h^{\cdot 1}\right)$ & $\left(\mathrm{nC} \mathrm{kg}^{-1} \mathrm{~h}^{-1}\right)$ \\
\hline $0+2090 \mathrm{~L}$ & 355 & 515.2 & 132.9 \\
\hline $0+2191 \mathrm{~L}$ & 220 & 302.3 & 78.0 \\
\hline $0+2391 \mathrm{~L}$ & 100 & 101.6 & 26.2 \\
\hline $0+4091 \mathrm{~L}$ & 40 & 39.0 & 10.1 \\
\hline $0+4875 \mathrm{~L}$ & 20 & 18.6 & 4.8 \\
\hline $2+2230 \mathrm{~L}$ & 18 & 33.0 & 8.5 \\
\hline $2+2226 \mathrm{~L}$ & 14 & 19.6 & 5.1 \\
\hline $4+0097 \mathrm{~L}$ & 13 & 17.1 & 4.4 \\
\hline $3+9812 R$ & 37 & 42.9 & 14.3 \\
\hline $3+9810 R$ & 23 & 30.0 & 9.8 \\
\hline $0+0254 \mathrm{R}$ & 25 & 20.7 & 6.5 \\
\hline $0+5835 R$ & 39 & 76.5 & 26.0 \\
\hline $0+5831 R$ & 30 & 50.4 & 16.9 \\
\hline $0+5824 \mathrm{R}$ & 20 & 27.4 & 8.9 \\
\hline
\end{tabular}


where

$$
\begin{aligned}
y & =\text { predicted exposure rate }\left(\mathrm{nC} \mathrm{kg}^{-1} \mathrm{~h}^{-1}\right) \\
b_{0} & =\text { estimate for } \beta_{0}\left(\mathrm{nC} \mathrm{kg} \mathrm{h}^{-1}\right) \\
b_{1} & =\text { estimate for } \beta_{1}\left(\mathrm{nC} \mathrm{kg} \mathrm{h}^{-1} \mathrm{kcpm}^{-1}\right) \\
x & =\text { scintillator count rate }(\mathrm{kcpm})
\end{aligned}
$$

The data in Table 2 were sorted into descending order according to scintillator count rate and entered into a PC-based version of SAS ${ }^{*}$ and a linear regression was performed. The regression output appears in Fig. 9. The SAS switch generuting residual analysis data was set to provide the information on studentized residuals and Cook's D statistic shown in Fig. 9.

The studentized residual is the residual for a particular observation divided by its standard error, or the number of standard deviations that the observation differs from its predicted value using the parameter estimates. The Cook's D statistic is a measure of the change in the parameter estimates if they were recalculated using the original data set with a particular observation omilted.

Note that both the studentized residual and the Cook's D statistics generally increased with increasing values of $x$. Consequently, there were more outliers of greater magnitude as $x$ increased, and the data points obtained trom the higher values of $x$ were having too great an effect on the parameter estimates. In other words, the data points that deviate most from model predictions of values of $y$ were playing the greatest roles in determining those $y$ values.

A simple linear regression, however, is based on certain assumptions that are not valid in this case. The derivation of a simple regression assumes that $e$, the statistical error term, varies normally with mean zero and constant variance. The statistics described in the preceding paragraphs show that this assumption was not valid for this data set. Instead, the statistical error should increase monotonically with scintillator response.

To circumvent this mathematical obstacle, it was necessary to employ a weighted regression scheme. Such a procedure allows for a nonconstant variance by incorporating another variable, a relative weight, into the regression. The estimated values of $b$ in a weighted regression are calculated by minimizing

$$
\sum_{i=1}^{n} w_{i}\left(Y_{i}-b_{0}-b_{1} x_{i}\right)^{2}
$$

where

$$
w_{i}=\text { individual wcighting factors. }
$$

The second term in Eq. (3) is the quantity minimized in a simple regression. Ross (1987) derives the formulas for the new estimators.

"SAS is a registered trademark of SAS Institute, Inc., Cary, North Carolina. 


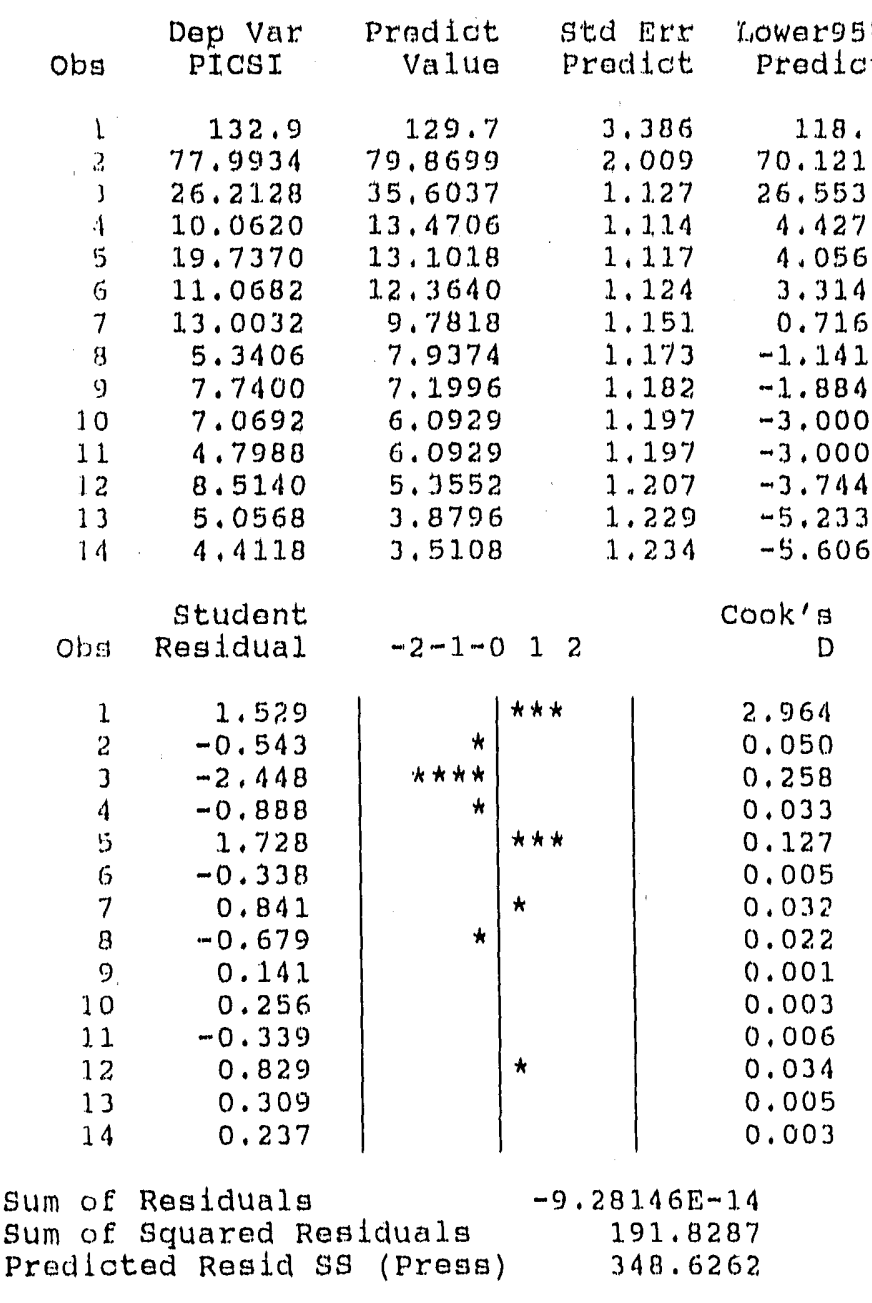

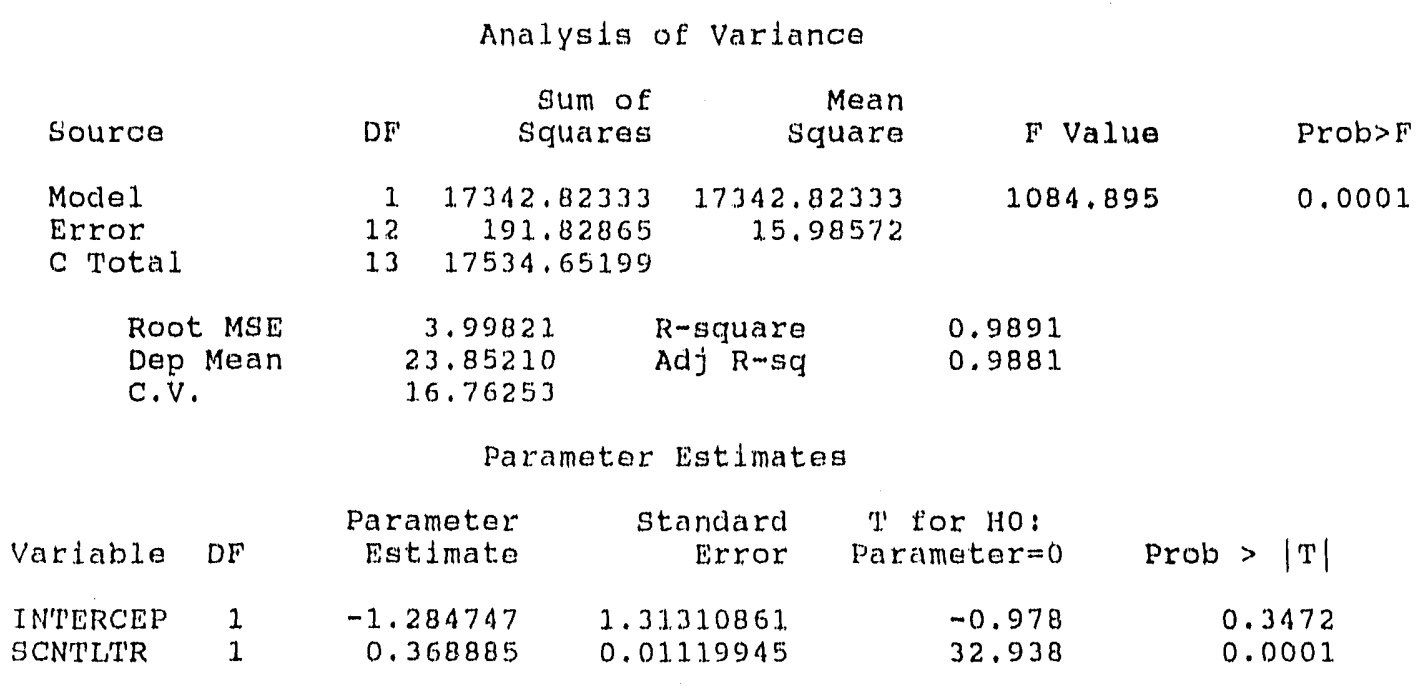

Fig. 9. Regression statistics for unweighted scheme. 
It was desired to give greater weight to l,uwer PIC roadings, hence, readings with lower variances. Ross (1987) shows that weights inversely proportional to the variance of the obscrvations provide best linear unbiased estimates for the parameters $b_{0}$ and $b_{1}$; radiation counts are Poisson distributed; thus, the estimate for the true varianed is the observation itself. The constant of proportionality is not needed in this case because the weights are relative, so unity was used as the proportionality constant. The data and the weights given by Eq. (4) were entered into SAS, where a weighted lincar regression was performed. The regression output appears as Fig. 10.

$$
w_{i}=\frac{1}{y_{i}}
$$

Note in the output for the unweighted regression that the studentized residuals are more cven in magnilude and that the larger values are more randomly distributed throughout the high and low values of scintillator count rate. Also, the Cook's D statistics for the higher scintillator count rates have been reduced significanlly; the high data points, where the model does not predict exposure rates as well, still alfect the parameter estimates most but to a much lesser degrec than in the unweighted schenic.

\subsection{DISCUSSION OF MODEL SIGNIFICANCE}

Before too much emphasis is placed here on the statistics generated from the data gathered, note that Draper and Smith (1981) state, "when $x$ is subject to error as well as $y$, the regression situation is considerably more complicatec'... For this reason it is always advantageous to arrange malters (if. possible) so that" the variance of the errors likely to occur in the $x$ data is small compared with the variance of the crrors likely to oceur in the $y$ data. "If this is not achicved, problems may arise if the usual analysis is carriced out."

This translates into how accurately the dependent and independent variables can be measured. In this case, the PIC provides a more accurate measure of exposure rate than does the scintillator. With this fact noted, the two SAS outputs are compared.

Figures 9 and 10 show the output generated by SAS. The columns show the relative weights given by Eq. (4); the values of the dependent variable (the PIC readings); the predicted values (those lying on the regression line); the standard error of the predicted values; $95 \%$ confidence limits; and information on residual analysis.

The analysis of varianee tables provide information on how well the linear model fits the data. The very large F stalistic is a measure of how much of the variation in the data is accounted for by the model in Eq. (2). The associated p-values represent the significance level at which the validity of the model would be rejecled. The tables indicate that the model accounts for the data to a $99.99 \%$ confidence level for both the weighted and unweighted regressions.

The parameter estimates table gives the estimated values of $b$ and the errors in their estimation. The T statistics and P-values are analogous to the model's $F$ statistic and p-value. Instead of the model's accounting for clata variation, the parameter statistics test the hypothesis that the parameters (the values of' $\beta$ ) are actually zero. Thus, for the unweighted 


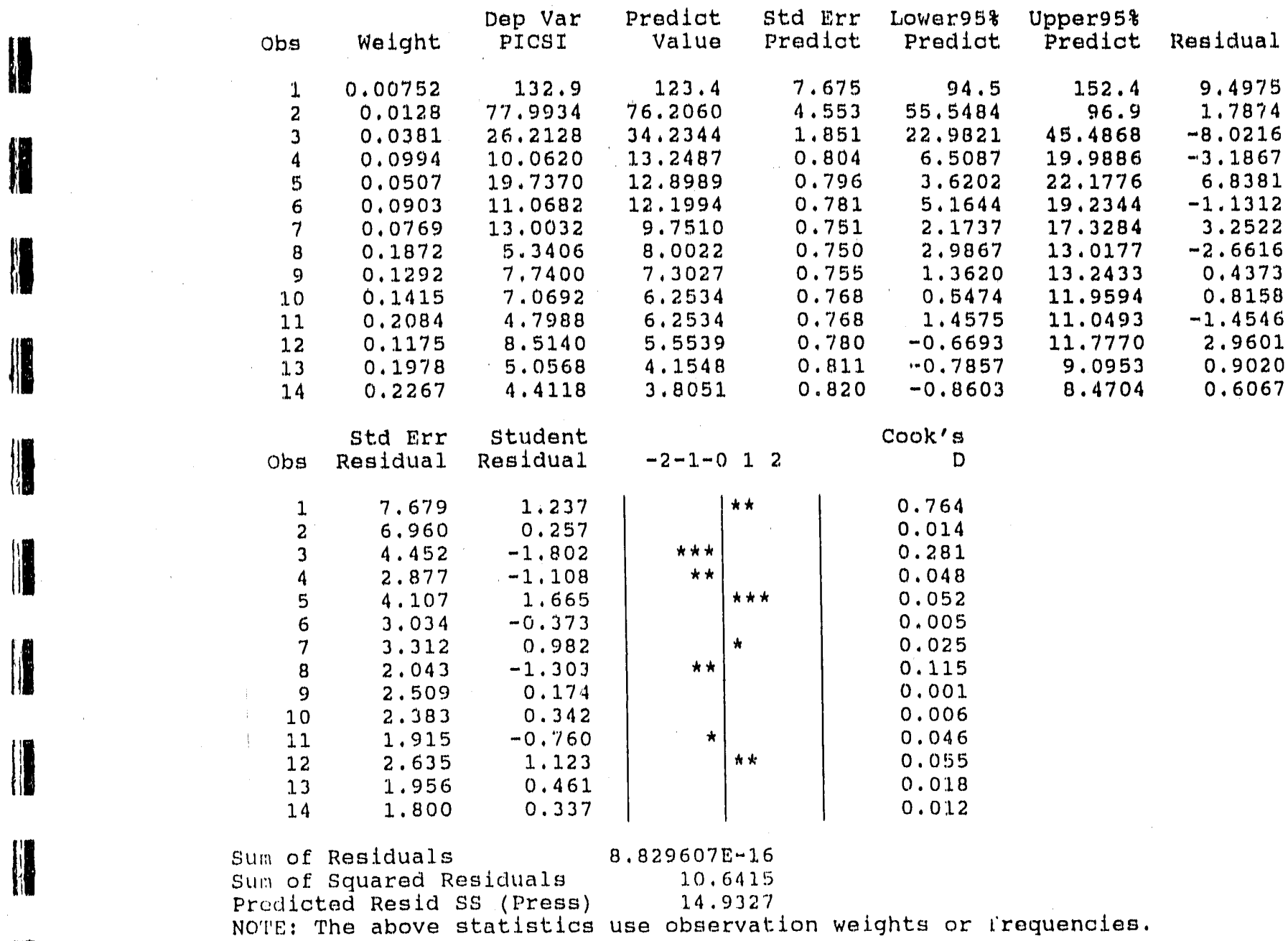

Analysis of Variance

\begin{tabular}{|c|c|c|c|c|c|}
\hline Source & $\mathrm{DF}$ & $\begin{array}{r}\text { Sum of } \\
\text { Squares }\end{array}$ & $\begin{array}{l}\text { Mean } \\
\text { Square }\end{array}$ & F Value & Prob $>F$ \\
\hline $\begin{array}{l}\text { Model } \\
\text { Error } \\
\text { C Total }\end{array}$ & $\begin{array}{r}1 \\
12 \\
13\end{array}$ & $\begin{array}{r}199.54722 \\
10.64147 \\
210.18869\end{array}$ & $\begin{array}{r}199.54722 \\
0.88679\end{array}$ & 225.022 & 0.0001 \\
\hline $\begin{array}{l}\text { Root MSE } \\
\text { Dep Mean } \\
\text { C.V. }\end{array}$ & & $\begin{array}{l}94169 \\
83862 \\
65432\end{array}$ & $\begin{array}{l}R-s q u a r e \\
A d j \quad R-s q\end{array}$ & $\begin{array}{l}0.9494 \\
0.9452\end{array}$ & \\
\hline
\end{tabular}

Parameter Estimates

$\begin{array}{lrrrrr}\text { Variable } & \text { DF } & \begin{array}{r}\text { Parameter } \\ \text { Estimate }\end{array} & \begin{array}{r}\text { Standard } \\ \text { Error }\end{array} & \begin{array}{r}\mathrm{T} \text { for HO: } \\ \text { Parameter=0 }\end{array} & \text { Frob }>|\mathrm{T}| \\ \text { INTERCEP } & 1 & -0.741865 & 0.98374438 & -0.754 & 0.4653 \\ \text { SCNTLTR } & 1 & 0.349763 & 0.02331639 & 15.001 & 0.0001\end{array}$

Fig. 10. Regression statisties for weighted scheme. 
regression, with $99.99 \%$ confidence, $\beta_{1}$ is nonzero. With $65 \%$ confidence, $\beta_{0}$ is nonzero. For the weighted regression, once again $\beta_{1}$ is nonzero with $99.99 \%$ confidence. With only $53.5 \%$ confidence, $\beta_{0}$ is nonzero.

Recall that the unweighted parameter estimates are the best linear unblased estimates for the true parameters, which means that although both regression schemes will provide unbiased estimates, the weighted estimates should have lower standard errors. However, Figs. 9 and 10 show that the linear estimate using the unweighted regression scheme has a lower standard error than the unweighted estimate. Even so, because of the increasing variation in PIC responses with increasing count rates and because the errors in measuring the scintillator count rate could skew the regression results, the weighted regression parameter estimates were used in the conversion of scintillator count rates to exposure rates. Discussions will heneforth refer only to the output from the unweighted regression.

Note that $b_{0}$, the estimate for the true intereept, is negative, which implies a negative predicted exposure rate for a scintillator response of $0 \mathrm{kcpm}$. Such a secmingly nonsensical conclusion is explained by recalling that $b_{0}$ is an estimate for $\beta_{0}$ and that " $\beta_{0}$ is not zero" is made with only $53.5 \%$ confidence. Consequently, there is not enough statistical evidence to support the claim that $\beta_{1}$ is nomzero. Even so, $b_{0}$ is the best estimate of the true intercept for the data. Although it is reasonable to assume that, idcally, an exposure rate of $0 \mathrm{nC} \mathrm{kg}^{-1} \mathrm{~h}^{-1}$ would give rise to a scintillator response of () $\mathrm{kcpm}$, it is neither technically feasible nor of concern here. The lowest scintillator eount rates, even when the instruments were tested indoors before each sortie into the field, were always in excess of $3 \mathrm{kcpm}$. So, although it is statistically reasonable to conclude that $b_{0}=0$ and recalculate a conversion factor with an intercept forced to zero, the statistics dictate that such a conclusion is unjustified in this case.

The p-value of the linear parameter estimate $\left(b_{1}\right)$ is quite low. Therefore, the assertion that $\beta_{l}$ is nonzero is made with a high degree of confidence, suggesting a nonzero linear relationship between count rate and exposure rate.

The formula used to convert scintillator count rates to exposure rates is given by Eq. (5),

$$
y=\left(-0.74 \mathrm{nC} \mathrm{kg}^{-1} \mathrm{~h}^{-1}\right)+\left(0.35 \mathrm{nC} \mathrm{kg}^{-1} \mathrm{~h}^{-1} \mathrm{kcpm}^{-1}\right) x .
$$

The question arises as to how ertain the exposure rate is predicted with a given scintillator count rate. The SAS output includes $95 \%$ confidence intervals for the predicted exposure rates for the data used in the regression. This output from SAS was used by SigmaPlot ${ }^{\dagger}$ to generate the graph in Fig. 11, which can be used for estimating the uncertainty in a single exposure: rate, given a certain scintillator count rate.

Calculation of these values is somewhat complicated. The interval is the standard error of the predieted exposure rate times a value drawn from a student's $t$ distribution, with the corresponding number of degrees of freedom and level of significance. The degrees of freedom associated with error is the number of observations less the number of parameters

'SigmaPlot is a registered trademark of Jandel Scientific, Inc., Corte Madera, California. 


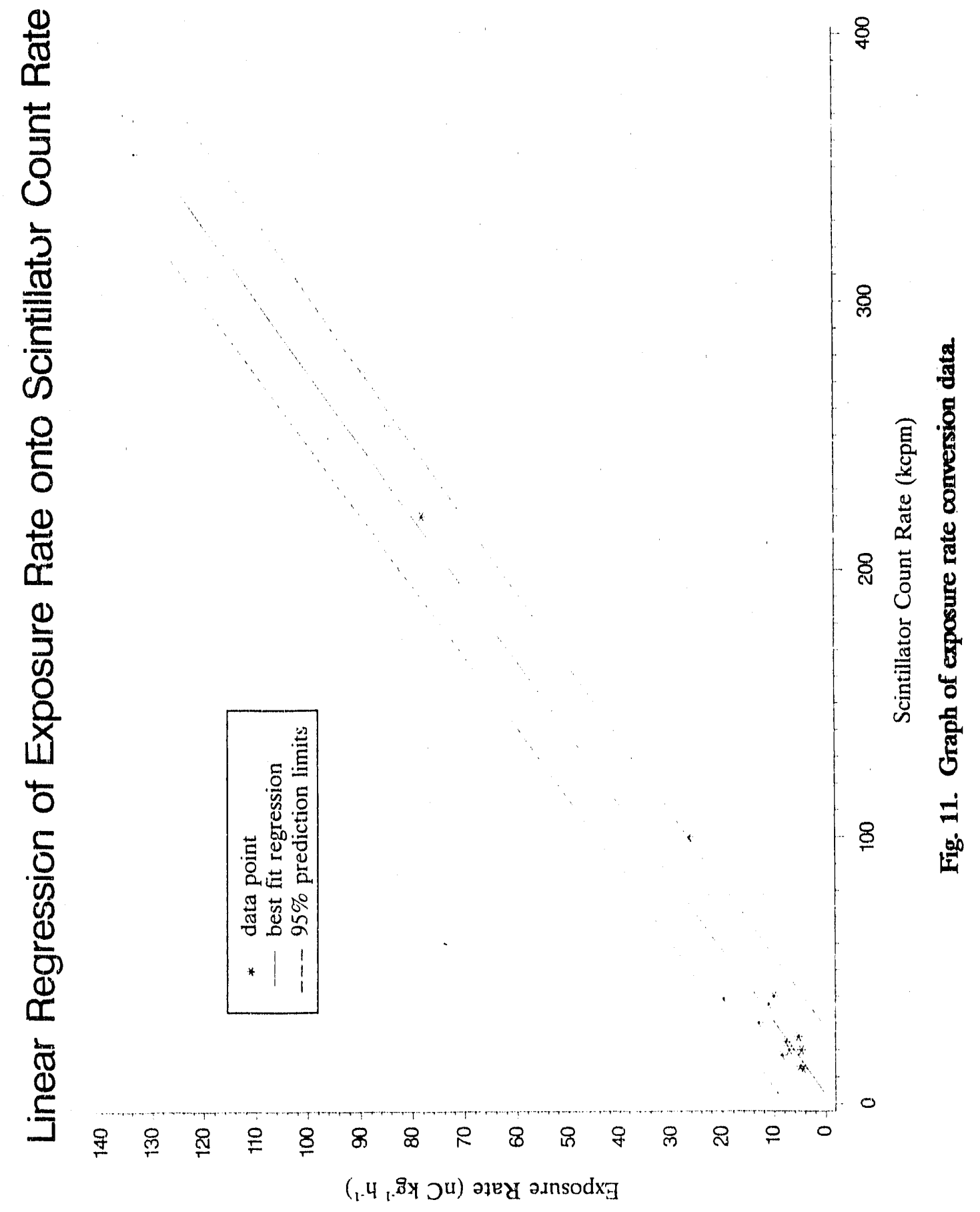


estimated by the model. For the data used in this model, the degrees of freedom is 12 . The standard error of the predicted exposure rate is given as

$$
\operatorname{StdErr}(\mathcal{y})=X_{0}^{T}\left(X^{T} W^{-1} X\right)^{-1} X_{0}
$$

where

$\operatorname{StdErr}(\hat{y})=$ standard error of the predicted exposure rate $\left(\mathrm{nC} \mathrm{kg}^{-1} \mathrm{~h}^{-1}\right)$,

$X_{0}=$ a colurnn vector consisting of a one (to pick up the intercept term) and the scintillate: eount rate for which the prediction is made (to pick up the linear term),

$X=$ a column vector containing all the scintillator count rates used in the regression model,

$W=$ a diagonal matrix with the $i$ th element being the variance of the errors divided by the $i$ th weighting factor.

The variance of the errors is unknown but can be estimated by the sum of squared residuals divided by the number of observations used in the model.

\subsection{BETA-GAMMA DOSE RATE CONVERSION}

The following formula was used to convert count rates measured with the beta-gamma pancake detector to human dose rate estimates:

$$
y=x R,
$$

where

$$
\begin{aligned}
y & =\text { aose rate }\left(\mu G y \mathrm{~h}^{-1}\right) \\
x & =\text { instrument count rate }(\mathrm{cpm}), \\
R & =\text { conversion factor }\left(\mu \mathrm{Gy} \mathrm{h} \mathrm{h}^{-1} \mathrm{cpm}^{-1}\right) .
\end{aligned}
$$

According to calibration calculations performed at ORNL [R. E. Swaja, Health and Safety Rescarch Division (HASRD), ORNL, personal communication to M. S. Uziel, HASRD, ORNL, June 23, 1989], using a Sr-Y source and various moderators, a conservative conversion factor for the type of detector used is $R=2.7 \times 10^{-3} \mu \mathrm{Gy} \mathrm{h}^{-1} \mathrm{cpm}^{-1}$. This conversion factor was computed based on data compiled with a polystyrene moderator with an areal density of $0.96 \mathrm{~g} \mathrm{~cm}^{-2}$ between the source and the detector, which was $38 \mathrm{~cm}$ away.

The sources encountered at Trench 5 consisted of strontium and cesium producing mixed beta-gamma. In some cases, the beta fields were moderated to an unknown extent. The conversion factor given represents a likely worst case to be found at Trench 5 and produces the highest dose rate estimates. 


\subsection{ALPHA ACTIVITY CONVERSION}

The following formula was used to convert count rates measured with the $\mathrm{ZnS}$ alpha probe to alpha surface activities:

$$
y=x R
$$

where

$$
\begin{aligned}
& y=\text { alpha activity }\left[\mathrm{Bq}\left(100 \mathrm{~cm}^{2}\right)^{-1}\right] \\
& x=\text { instrument count rate }(\mathrm{cpm}) \\
& R=\text { conversion factor }\left[\mathrm{Bq}\left(100 \mathrm{~cm}^{2}\right)^{-1} \mathrm{cpm}^{-1}\right]
\end{aligned}
$$

The instrument calibration is performed at ORNL, and the conversion factor $R$ is reported to the MAD instrument manager for each probe. For the Trench 5 survey, $R=0.15 \mathrm{~Bq}\left(100 \mathrm{~cm}^{2}\right)^{-1} \mathrm{cpm}^{-1}\left[9 \mathrm{dpm}\left(100 \mathrm{~cm}^{2}\right)^{-1} \mathrm{cpm}^{-1}\right]$.

The surfaces checked for alpha activity at the Trench 5 site were generally nonplanar, which means that only a portion of the $100 \mathrm{~cm}^{2}$ detector surface was being used. Consequently, the true surface activities are probably higher than reported.

\subsection{SMEAR COUNTING}

The minimum detectable activity (MDA) of a counting device is defined as the smallest amount of activity present in the counting chamber that would result in a statistically significant count. A statistically significant count rate is one high enough over the mean background count rate to be able to reject the hypothesis with a specific degree of certainty (usually 95\%) that there is no activity in the specimen being counted. A count resulting in a calculated activity in the specimen lower than the MDA indicates that, although there may indeed be scme activity present, one cannot assert with the degree of confidence used in calculating the MDA that there is any activity in the specimen. Factors that affect the MDA are background count rate and count time, sample count rate and time, and the counting geometry used.

The MDA of the alpha counting system was $117 \mathrm{mBq}(7 \mathrm{dpm})$ for a 3-min count. The conversion factor from count rate to activity given for this detector was $47 \mathrm{mBq} \mathrm{cpm}^{-1}$ $\left(2.8 \mathrm{dpm} \mathrm{cpm}{ }^{-1}\right)$. The MDA of the beta counting system was $3.1 \mathrm{~Bq}(183 \mathrm{dpm})$ for a 5 -min count. Its efficiency for ${ }^{90} \mathrm{Sr}$ was $9.5 \%$. Both MDAs represent a $95 \%$ level of confidence. 


\section{RESULTS}

\subsection{BACKGROUND LEVELS}

Background gamma radiation levels at uncontaminated areas at Trench 5 were detected with the NaI scintillators at each grid intersection, both at the ground and at a height of $1 \mathrm{~m}$ (Table 3 and Fig. 7). White Oak Creek flows in a valley near Trench 5, and its floodplain extends into the gully bordering the east side of the area surveyed. As a result, gamma fields in this region are somewhat elevated. This elevation is evidenced by the higher grid point readings in the southeastern corner of the surveyed area. The higher count rates at these locations are most likely the emanation or "shine" from White Oak Creek and its floodplain. The consistently higher exposure rates at $1 \mathrm{~m}$ versus those at the surface supports this conclusion. Over most areas, the grid point exposure rates are in the range of 4 to $7 \mathrm{nC} \mathrm{kg}^{-1} \mathrm{~h}^{-1}$ although exposure rates in the southern and eastern portions of the grid are generally higher.

Systematic soil samples from Trench 5 were counted for background activity. Construction at Trench 5 allowed only three samples to be included in the background characterization. Such limited sampling is not statistically meaningful, but it does provide a basis from which generalizations may be extrapolated. The activity reports for these samples appear in the following sections of this report. 
Table 3. Exposure rates at grid intersections at Trench 5

\begin{tabular}{|c|c|c|c|c|}
\hline \multirow[b]{2}{*}{ Grid location } & \multicolumn{2}{|c|}{$\begin{array}{l}\text { Nal count rate } \\
(\mathrm{kcpm})\end{array}$} & \multicolumn{2}{|c|}{$\begin{array}{l}\text { Exposure rate } \\
\left(\mathrm{nC} \mathrm{kg}^{-1} \mathrm{~h}^{-1}\right)\end{array}$} \\
\hline & $\begin{array}{l}1 \mathrm{~m} \text { above } \\
\text { ground }\end{array}$ & Surface & $\begin{array}{l}1 \mathrm{~m} \text { above } \\
\text { ground }\end{array}$ & Surface \\
\hline $0+00100 \mathrm{~L}$ & 30 & 27 & 10.5 & 9.4 \\
\hline $0+50$ & 28 & 22 & 9.8 & 7.7 \\
\hline $1+\infty$ & 18 & 16 & 6.3 & 5.6 \\
\hline $1+50$ & 17 & 17 & 5.9 & 5.9 \\
\hline $2+\infty 0$ & 17 & 17 & 5.9 & 5.9 \\
\hline $2+50$ & 14 & 14 & 4.9 & 4.9 \\
\hline $3+00$ & 15 & 15 & 5.2 & 5.2 \\
\hline $3+50$ & 15 & 15 & 5.2 & 5.2 \\
\hline $4+00$ & 10 & 10 & 3.5 & 3.5 \\
\hline $4+50$ & 15 & 14 & 5.2 & 4.9 \\
\hline $5+00$ & 14 & 13 & 4.9 & 4.5 \\
\hline $0+0050 \mathrm{~L}$ & 23 & 20 & 8.0 & 7.0 \\
\hline $0+50$ & 20 & 18 & 7.0 & 6.3 \\
\hline $1+00$ & 18 & 16 & 6.3 & 5.6 \\
\hline $1+50$ & 17 & 16 & 5.9 & 5.6 \\
\hline $2+\infty$ & 14 & 14 & 4.9 & 4.9 \\
\hline $2+50$ & 15 & 13 & 5.2 & 4.5 \\
\hline $3+00$ & 15 & 13 & 5.2 & 4.5 \\
\hline $3+50$ & 14 & 14 & 4.9 & 4.9 \\
\hline $4+00$ & 13 & 13 & 4.5 & 4.5 \\
\hline $4+50$ & 13 & 12 & 4.5 & 4.2 \\
\hline $5+00$ & 13 & 12 & 4.5 & 4.2 \\
\hline $0+00 \mathrm{BL}$ & 19 & 18 & 6.6 & 6.3 \\
\hline $0+50$ & 17 & 16 & 5.9 & 5.6 \\
\hline $1+00$ & 18 & 16 & 6.3 & 5.6 \\
\hline $1+50$ & 17 & 15 & 5.9 & 5.2 \\
\hline $2+00$ & 14 & 13 & 4.9 & 4.5 \\
\hline $2+50$ & 12 & 11 & 4.2 & 3.8 \\
\hline $3+00 \mathrm{BL}$ & 12 & 10 & 4.2 & 3.5 \\
\hline $3+50$ & 11 & 10 & 3.8 & 3.5 \\
\hline
\end{tabular}


Table 3 (continued)

\begin{tabular}{|c|c|c|c|c|}
\hline \multirow[b]{2}{*}{ Grid location } & \multicolumn{2}{|c|}{$\begin{array}{l}\text { Nal count rate } \\
(\mathrm{kcpm})\end{array}$} & \multicolumn{2}{|c|}{$\begin{array}{l}\text { Exposure rate } \\
\left(\mathrm{nC} \mathrm{kg}^{-1} \mathrm{~h}^{-1}\right)\end{array}$} \\
\hline & $\begin{array}{l}1 \mathrm{~m} \text { above } \\
\text { ground }\end{array}$ & Surface & $\begin{array}{l}1 \mathrm{~m} \text { above } \\
\text { ground }\end{array}$ & Surface \\
\hline $4+\infty$ & 14 & 12 & 4.9 & 4.2 \\
\hline $4+50$ & 13 & 11 & 4.5 & 3.8 \\
\hline $5+00$ & 13 & 12 & 4.5 & 4.2 \\
\hline $0+0050 \mathrm{R}$ & 24 & 23 & 8.4 & 8.0 \\
\hline $0+50$ & 21 & 18 & 7.3 & 6.3 \\
\hline $1+\infty$ & 20 & 19 & 7.0 & 6.6 \\
\hline $1+50$ & 18 & 17 & 6.3 & 5.9 \\
\hline $2+\infty 0$ & 17 & 17 & 5.9 & 5.9 \\
\hline $2+50$ & 15 & 15 & 5.2 & 5.2 \\
\hline $3+00$ & 15 & 14 & 5.2 & 4.9 \\
\hline $3+50$ & 15 & 14 & 5.2 & 4.9 \\
\hline $4+\infty 0$ & 14 & 13 & 4.9 & 4.5 \\
\hline $4+50$ & 14 & 12 & 4.9 & 4.2 \\
\hline $5+00$ & 13 & 12 & 4.5 & 4.2 \\
\hline $0+00100 R$ & 24 & 20) & 8.4 & 7.0 \\
\hline $0+50$ & 22 & 20 & 7.7 & 7.0 \\
\hline $1+00$ & 14 & 16 & 4.9 & 5.6 \\
\hline $1+50$ & 16 & 16 & 5.6 & 5.6 \\
\hline $2+00$ & 16 & 15 & 5.6 & 5.2 \\
\hline $2+50$ & 12 & 10) & 4.2 & 3.5 \\
\hline $3+00$ & 14 & 12 & 4.9 & 4.2 \\
\hline $3+50$ & 14 & 14 & 4.9 & 4.9 \\
\hline $4+00$ & 13 & 13 & 4.5 & 4.5 \\
\hline $4+50$ & 14 & 14 & 4.9 & 4.9 \\
\hline $5+00$ & 12 & 11 & 4.2 & 3.8 \\
\hline
\end{tabular}




\subsection{SURFACE GAMMA SCAN}

Results of the surface gamma scan at Trench 5 are shown in Fig. 8. The approximate locations of highly iocalized contamination points or hot spots, depicted by shaded ellipses, are shown on the figure. Sampling locations, PIC data collection locations, and regions of areal contamination are also shown.

Numerous hot spots of elevated gamma exposure rates were identified over most of the surveyed areas. These points were generally small and of relatively low intensity: $<40 \mathrm{nC} \mathrm{kg}^{-1} \mathrm{~h}^{-1}\left(155 \mu \mathrm{R} \mathrm{h}^{-1}\right)$ in most cases. However, some locales with high radiation fields were located. Several corrugated metal vents protruding through the cover over the trench provided gamma sources beneath the asphalt an unshielded radiation path to the surface. The fields from these vents were highly collimated beams rising vertically from the surface and decreasing in intensity with height above the suriace. Surface exposure rates, measured with a cutie pie, were as high as $3100 \mathrm{nC} \mathrm{kg}^{-1} \mathrm{~h}^{-1}\left(12 \mathrm{mR} \mathrm{h}^{-1}\right)$. A well in 4+00 BL exhibited high radiation readings, at $227 \mathrm{nC} \mathrm{kg}^{-1} \mathrm{~h}^{-1}\left(0.88 \mathrm{mR} \mathrm{h}^{-1}\right)$.

Pieces of piping lying beside the trench were contaminated to varying degrees. Exposure rates from these ranged from 28 to $3100 \mathrm{nC} \mathrm{kg}^{-1} \mathrm{~h}^{-1}\left(0.11\right.$ to $\left.12 \mathrm{mR} \mathrm{h}^{-1}\right)$.

A valve in $0+00100 \mathrm{~L}$, properly marked for radiological hazards, yielded exposure rates as high as $21 \mu \mathrm{C} \mathrm{kg}^{-1} \mathrm{~h}^{-1}\left(80 \mathrm{mR} \mathrm{h}^{-1}\right)$ on contact, with readings dropping off to about $1 \mu \mathrm{C}$ $\mathrm{kg}^{-1} \mathrm{~h}^{-1}\left(4 \mathrm{mR} \mathrm{h}^{-1}\right)$ at $1 \mathrm{~m}$. Based on the values reported here, the area is actually classified as being more dangerous than the exposure rate warrants. Note in Figs. 7 and 8 that this valve is situated adjacent to the access road, but significant exposure to the field from the valve is unlikely because of infrequent traffic.

\subsection{BETA-GAMMA MEASUREMENTS}

Beta-gamma checks were made intermittenlly where beta contamination was considered pessible, and activity was detected at a number of locations near the trench. Pipes near the trench at five separate locations exhibited surface beta activity. Table 4 summarizes the findings at these sites. Note that in some cases the radiation ficlds saturated the detection instrument. In these cases, only the location at which the instrument became saturated was reported.

Beta contamination was noted in three redbud trees along the treeline at the northern end of the trench. Their locations are shown in Fig. 8. The highest dose rates discovered were about $2 \mu \mathrm{Gy} \mathrm{h}^{-1}\left(0.2 \mathrm{mrad} \mathrm{h}^{-1}\right)$. The soil and vegetable matter under these trees contained some beta contamination because of the deciduous cycle of the trees (see Sect. 5.5); measured dose rates were approximately an order of magnitude lower than those from the trees. The immediate area was checked for additional contaminated trees; none were detected. 
Table 4. Summary of pipe surveys at Trench 5

\begin{tabular}{cccc}
\hline Grid block & $\begin{array}{c}\text { Exposure rate } \\
\left(\mathrm{nC} \mathrm{kg}^{-1} \mathrm{~h}^{-1}\right)\end{array}$ & $\begin{array}{c}\text { Dose rate } \\
\left(\mu \mathrm{Gy} \mathrm{h} \mathrm{h}^{-1}\right)\end{array}$ & $\begin{array}{c}\text { Alpha activity } \\
{\left[\mathrm{dpm}\left(100 \mathrm{~cm}^{2}\right)^{-1}\right]}\end{array}$ \\
\hline $0+50 \mathrm{BL}$ & 70 & $>810$ & 459 \\
$1+50 \mathrm{BL}$ & 28 & $>810$ & $<\mathrm{MDA}$ \\
$2+0050 \mathrm{~L}$ & 42 & 31 & 207 \\
$2+50 \mathrm{BL}$ & 105 & $>810$ & $<\mathrm{MDA}$ \\
$3+0050 \mathrm{~L}$ & 3100 & 240 & 234 \\
\hline
\end{tabular}

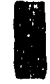




\subsection{ALPHA MEASUREMENTS}

A determination of the presence of alpha radiation was made in certain instances. The only places checked were the exterior surfaces of loreign objects-that is, on items that are not naturally tenable to a sylvan setting, such as the pipes and pumping apparatus strewn about the site. Table 4 shows $t$ ' : results of alpha radiation measurements.

\subsection{SOIL AND VEGETATION SAMPLE ANALYSES}

Results of analyses of soil and vegetation samples showed ${ }^{137} \mathrm{Cs}$ and, in certain areas, ${ }^{90} \mathrm{Sr}$ to be the dominant radionuclides. The locations of the sampling sites are shown in Fig. 8.

The computer that controlled the gamma spectral analysis of the samples generated comprchensive activity reports for each sample. A summary of the relevant information provided by the analysis appears in Table 5. Samples with the identification (ID) prefix $B$ are the biased samples; samples with the ID prefix S are the systematic samples.

The only isotopes of relevance in these analyses were ${ }^{137} \mathrm{C}$ s and ${ }^{60} \mathrm{Co}$. Cesium dominates the samples by several orders of magnitude over cobalt. Though trace amounts uit other radionuclides were detected in some samples, there is no reason to believe that those activities are anything other than typical background concentrations. 


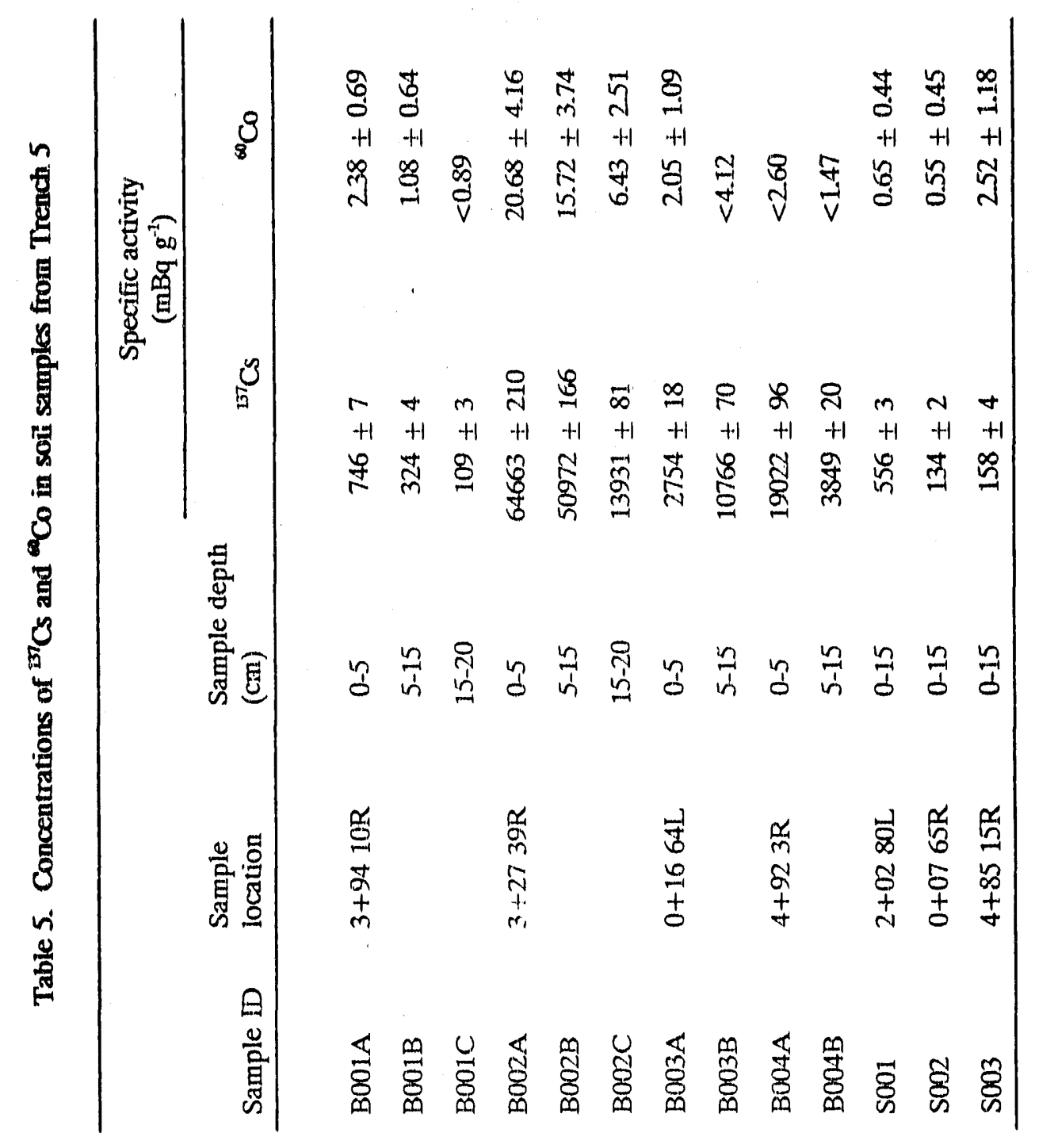


Leaves from the contaminated trees, along with soil samples from beneath the trees, were submitted to the Analytical Chemistry Division for strontium analysis after it was discovered that the trees demonstrated detectable levels of beta activity. The results of this analysis appear in Table 6.

\subsection{SMEAR ANALYSIS}

Surfaces expected to have possible removable contamination were smeared using standard smear paper. Approximately $100 \mathrm{~cm}^{2}$ was smeared for each sample. The locations and results of these smears appear in Table 7.

Note that not all of the pipes demonstraled signs of removable contamination, and in no case was any removable alpha activity detected. In addition, the vents and wells with the collimated gamma fields exhibited no removable contamination. 
Table 6. Summary of radiechemical analysis performed by the Analytical Chemistry Division

\begin{tabular}{ccc}
$\begin{array}{c}\text { Sample } \\
\text { ID }\end{array}$ & Location & $\begin{array}{c}\text { Sr activity } \\
\left(\mathrm{Bq} \mathrm{kg}^{-1}\right)\end{array}$ \\
\hline B001A & $3+9410 \mathrm{R}$ & $1600 \pm 200$ \\
$\mathrm{~V} 001$ & $3+8522 \mathrm{R}$ & $65 \times 10^{3} \pm 2000$ \\
$\mathrm{~V}(0) 2$ & $4+0620 \mathrm{R}$ & $8500 \pm 700$ \\
\hline
\end{tabular}


Table 7. Analysis results of smears at Tronch 5

\begin{tabular}{lrrrr}
\hline $\begin{array}{c}\text { Material smearcd, } \\
\text { location }\end{array}$ & $\begin{array}{c}\text { Alpha } \\
\text { count } \\
(\mathrm{cpm})\end{array}$ & $\begin{array}{c}\text { Alpha } \\
\text { activity } \\
(\mathrm{mBq})\end{array}$ & $\begin{array}{r}\text { Beta } \\
\text { count } \\
(\mathrm{cppm})\end{array}$ & $\begin{array}{c}\text { Beta } \\
\text { activity } \\
(\mathrm{Bq})\end{array}$ \\
\hline Mctal pipes, 0+50 BL & 0.0 & $<\mathrm{MDA}$ & 867.3 & 152.2 \\
Metal pipes, 0+50 BL & 0.0 & $<\mathrm{MDA}$ & 202.7 & 35.6 \\
Metal pipes, 0+50 BL & 0.7 & $<\mathrm{MDA}$ & 1987.7 & 348.7 \\
Metal pipes, 2+00 50L & 0.3 & $<\mathrm{MDA}$ & 20.3 & 3.6 \\
Metal pipes, 2+00 50L & 0.0 & $<\mathrm{MDA}$ & 18.7 & 3.3 \\
Motal pipes, 2+50 50L & 0.3 & $<\mathrm{MDA}$ & 8.7 & $<\mathrm{MDA}$ \\
Metal pipes, 3+00 50L & 0.0 & $<\mathrm{MDA}$ & 434.0 & 76.1 \\
Metal pipes, 3+00 50L & 0.7 & $<\mathrm{MDA}$ & 385.3 & 67.6 \\
Metal pipes, 3+00 50L & 0.3 & $<\mathrm{MDA}$ & 263.3 & 46.2 \\
Metal pipes, 3+00 50L & 0.0 & $<\mathrm{MDA}$ & 12.0 & $<\mathrm{MDA}$ \\
Well valve, 4+00 BL & 0.0 & $<\mathrm{MDA}$ & 5.7 & $<\mathrm{MDA}$ \\
Inside well, 4+00 BL & 0.0 & $<\mathrm{MDA}$ & 88.3 & 15.5 \\
Metal pipes, 1+50 BL & 1.3 & $<\mathrm{MDA}$ & 424.0 & 74.4 \\
Metal pipes, 1+50 BL & 0.7 & $<\mathrm{MDA}$ & 860.7 & 151.0 \\
\hline
\end{tabular}




\section{CONCLUSIONS AND RECOMMENDATIONS}

\subsection{CRITERIA}

As defined by ORNL, the entire WAG 7 locale is a Controlled Area. Aceess is restricted by a fence surrounding the area and a badge-reader aceess control entrance gate. Within Controlled Areas, ORNL defines three applicable levels of radiation fields (P. F. Tiner, HASRD, ORNL, personal communication to D. D. Goff, The University of 'Tennessee, Knoxville, April 1991):

- Radiation arca: any accessible area where whole body dose equivalent rates are between 30) and $1000 \mu \mathrm{Sv} \mathrm{h}^{-1}\left(3\right.$ and $\left.100 \mathrm{mrem} \mathrm{h}^{-1}\right)$.

- High radiation area: any accessible area where whole-body dose equivalent rates are between 1 and $50 \mathrm{mSv} \mathrm{h}^{-1}\left(100\right.$ and $\left.5000 \mathrm{mrem} \mathrm{h}^{-1}\right)$.

- Very high :adiation area: any accessible area where whole-body dose equivalent rates are greater than $50 \mathrm{mSv} \mathrm{h}^{-1}\left(5 \mathrm{rem} \mathrm{h}^{-1}\right)$.

All values assume a distance of $30 \mathrm{~cm}$ from the source or from any surface through which the radiation penetrates.

ORNL also delines guidelines for determining the contamination status of work surfaces, tools, and equipment. Any item exceeding the following activity levels is deemed contaminated (P. F. Tiner, HASRD, ORNL, personal communication to D. D. Golf, The University of Tennessee, Knoxville, April 1991):

- Transferable smear activily of $0.33 \mathrm{~Bq}\left(100 \mathrm{~cm}^{2}\right)^{-1}\left[20 \mathrm{dpm}\left(100 \mathrm{~cm}^{2}\right)^{-1}\right]$ for alpha emilters and $3.3 \mathrm{~Bq}\left(100 \mathrm{~cm}^{2}\right)^{-1}\left[200 \mathrm{dpm}\left(100 \mathrm{~cm}^{2}\right)^{-1}\right]$ for beta-gamma emitters.

- Contact readings of $5.0 \mathrm{~Bq}\left(100 \mathrm{~cm}^{2}\right)^{-1}\left[300 \mathrm{dpm}\left(100 \mathrm{~cm}^{2}\right)^{-1}\right]$ for alpha activity and 16.7 $\mathrm{Bq}\left(100 \mathrm{~cm}^{2}\right)^{-1}\left[1000 \mathrm{dpm}\left(100 \mathrm{~cm}^{2}\right)^{-1}\right]$ for beta-gamma activity.

\subsection{RECOMMENDATIONS FOR CORRECTIVE ACTIONS}

Localized areas of elevated gamma exposure rates, radioactive contaminants in soil and trees, and radioactively contaminated debris on the ground warrant corrective measures. The conclusions presented here are based solely on the results of this survey, which is a preliminary evaluation and not a detailed radiological characterization. In kecping with the spirit of the concept of as low as reasonably achlevable (ALARA), the primary goals of any corrective actions are to minimize human exposure to radiation and insult to the environment. With ALARA and ORNL radiation salety policies in mind, the following actions are recommended:

- The surface of the asphalt over the trench is damaged in several places. Relatively small cracks and holes have appeared apparently by means of temperature variation-induced heat stress. Although no radiation was detected at any of these points, they do represent physical hazards and could compromise the integrity of the trencti. These defects could be casily repaired to avold subsequent complications.

- Many pieces of scrap metal, plastic, and rubber materials were found near the trench (sec Figs. 12 and 13). All of these items represent physical hazards to mowing operations in the area. Additionally, some metal pipes were found to be contaminated to varying degrees. All of these materials should be removed and disposed of properly. 


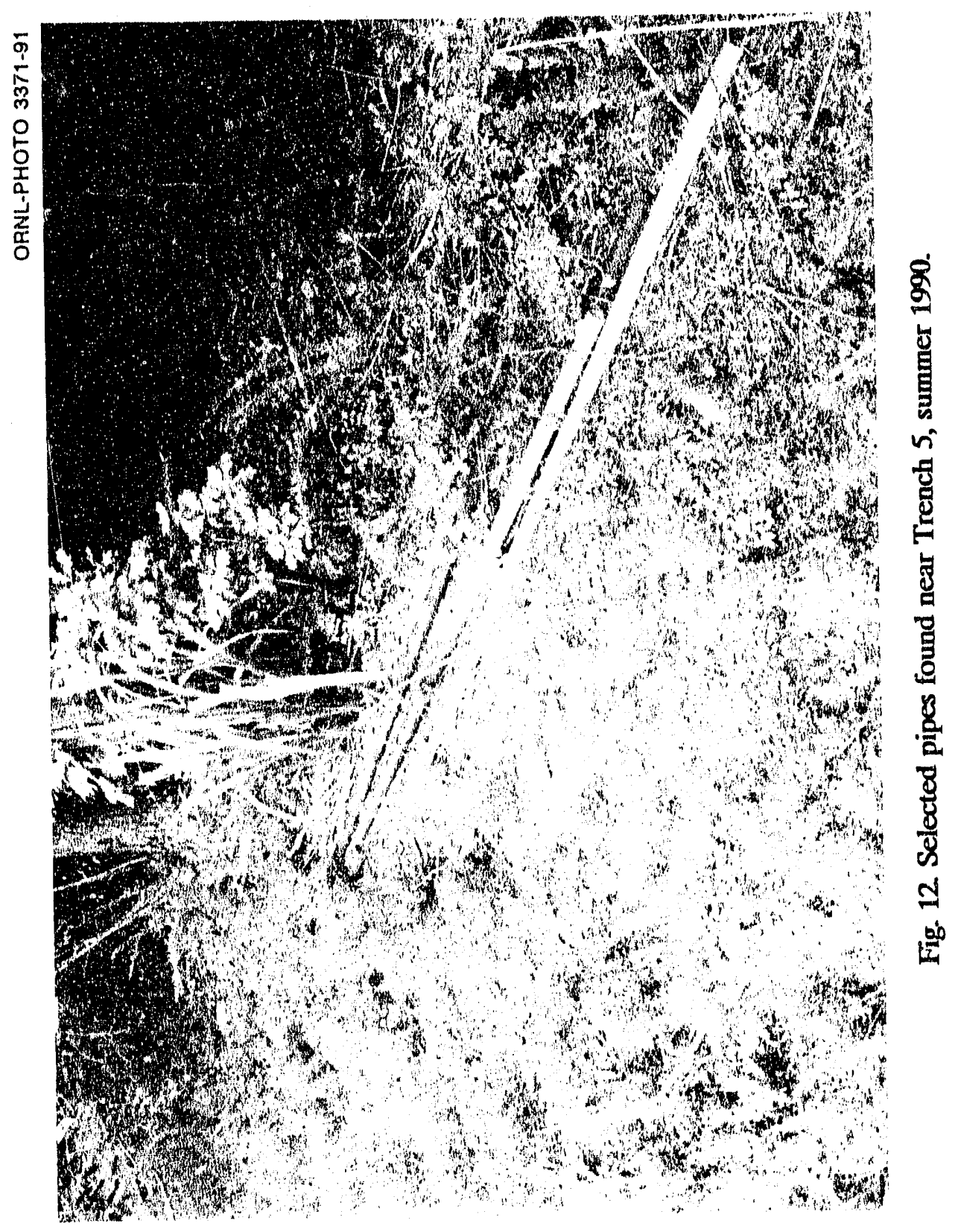




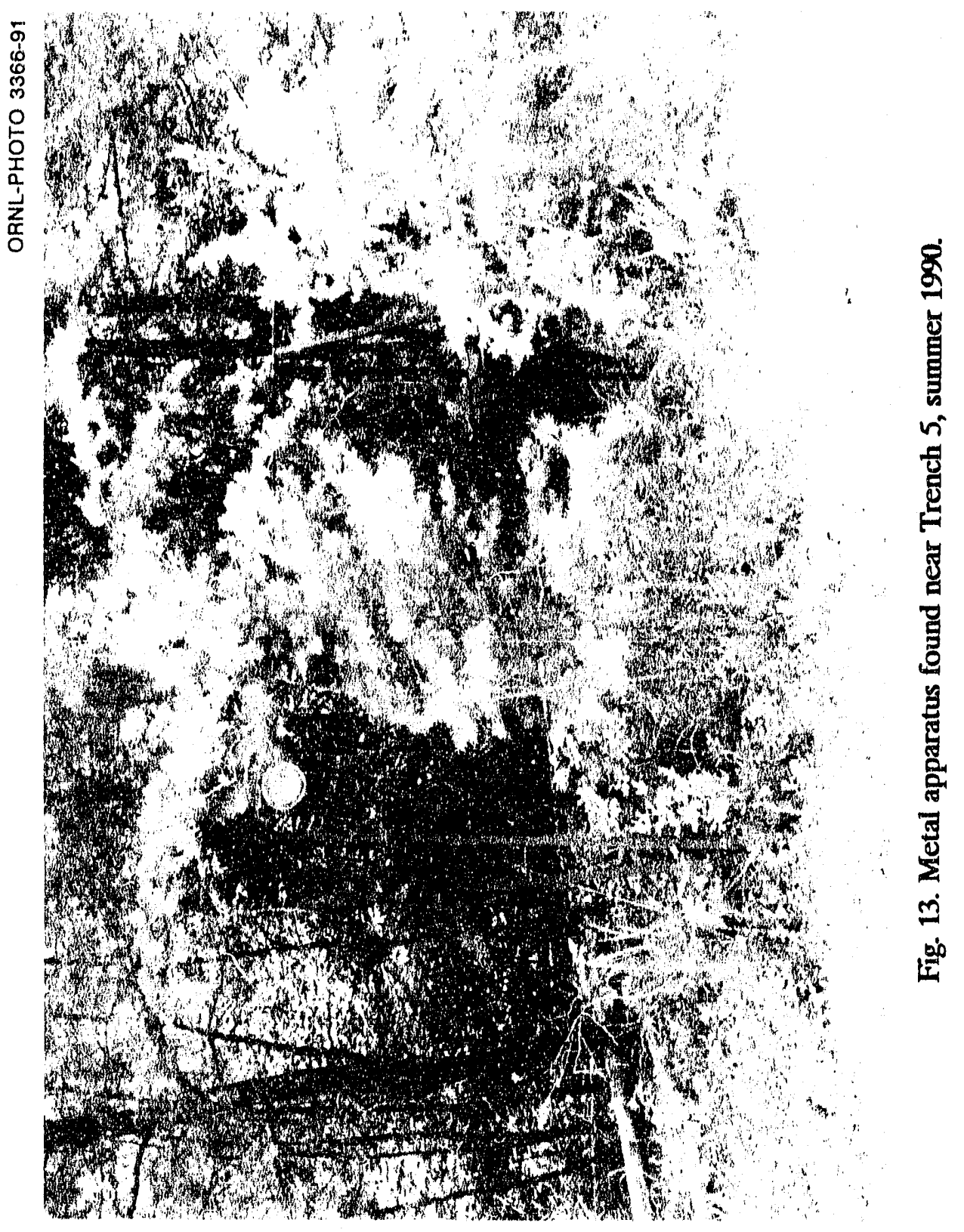


- Only one radiological hazard warning sign is posted at the trench itself. Although this sign is visible from the road approaching the trench, it is not visible from the parking area near the monitoring wells nor to anyone approaching the trench from somewhere other than the road. Additional warning signs emplaced around the trench would alleviate this potential safety hazard.

- The well at the northern end of the trench in grid block $3+50 \mathrm{BL}$ is a source of a highly collimated gamma field with exposure rates significant enough to classify it as a High Radiation Area (see Fig. 14). A sign similar to that at the valve at the southern end of the trench (see Figs. 15 and 16) should be put in place.

- Several redbud trees along the eastern treeline and between the well at the northern end of the trench and the trench itself exhibited beta-gamma contamination. The trees are located near the area of widespread surface soil contamination within several meters of the trench, indicating probable root uptake. To minimize further migration of radionuclides from the trench, the affected trees should be cut down, removed, and disposed of properly. As a precaution against this same phenomenon occurring with other trees in the immediate vicinity, additional removals might be considered. Recessing the treeline in an area between the trench and the contaminated well might avoid a similar situation in the future. Another option, short of removal of the trees, would be to rope off the affected area and emplace radiation hazard signs. Destroying the trees and leaving the root systems in the ground would allow the radionuclides in the roots to be leached out and into the subsurface soil.

\subsection{GENERAL OBSERVATTONS}

Although the MAD Group has traditional procedures for all the techniques used in the characterization of Trench 5, some departures were made from them in preparing this document. Ordinarily, a simple regression is performed to obtain a conversion from scintillator count rate to exposure rate without statistically testing parameter or model hypotheses or examining the residuals. It is recommended that those extra tasks be performed to detect anomalies such as the nonconstant variance of the errors observed in this project. It is believed that in this case, the recalculation of the parameter estimates and the statistical quantitics derived from them was warranted. However, because it is believed that the current method leaves too much uncertainty in the results, techniques involving the conversion process from count rate to exposure rate are suggested for future work or experimentation with the status quo.

The data sets submitted to a linear least-squares regression analysis on one predictor variable consist of two variables: an independent variable whose magnitude is adjusted and an observed dependent variable whose response is proportional to the input variable. It is assumed that measurement of the input is subject to very small errors when compared with the measurement errors of the response. It is believed that this condition would be met to a greater degree by regressing count rate onto exposure rate rather than vice versa. Draper and Smith (1981) cite extensive literature on attempting linear analysis when both variables are subject to similar errors in their measurements.

By measuring the exposure rate with the PIC, a very accurate determination of the exposure rate is made, with accuracy increasing with integration times. Scintillator count rate, presumably, will be linearly related to the field driving the detector. Once the data are 


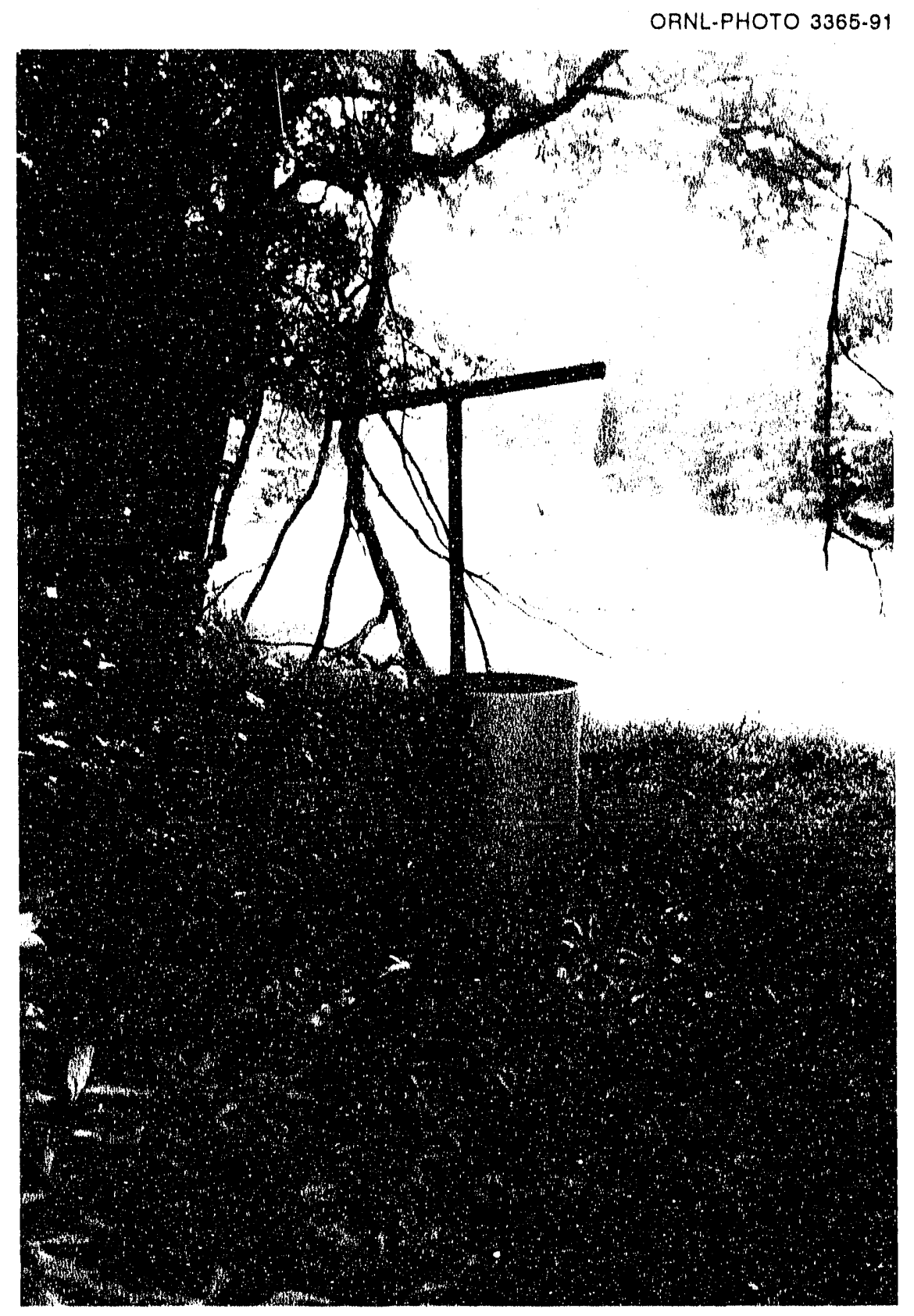

Fig. 14. Well at the northern end of Trench 5 exhibiting elevated exposure rates, summer 1990. 


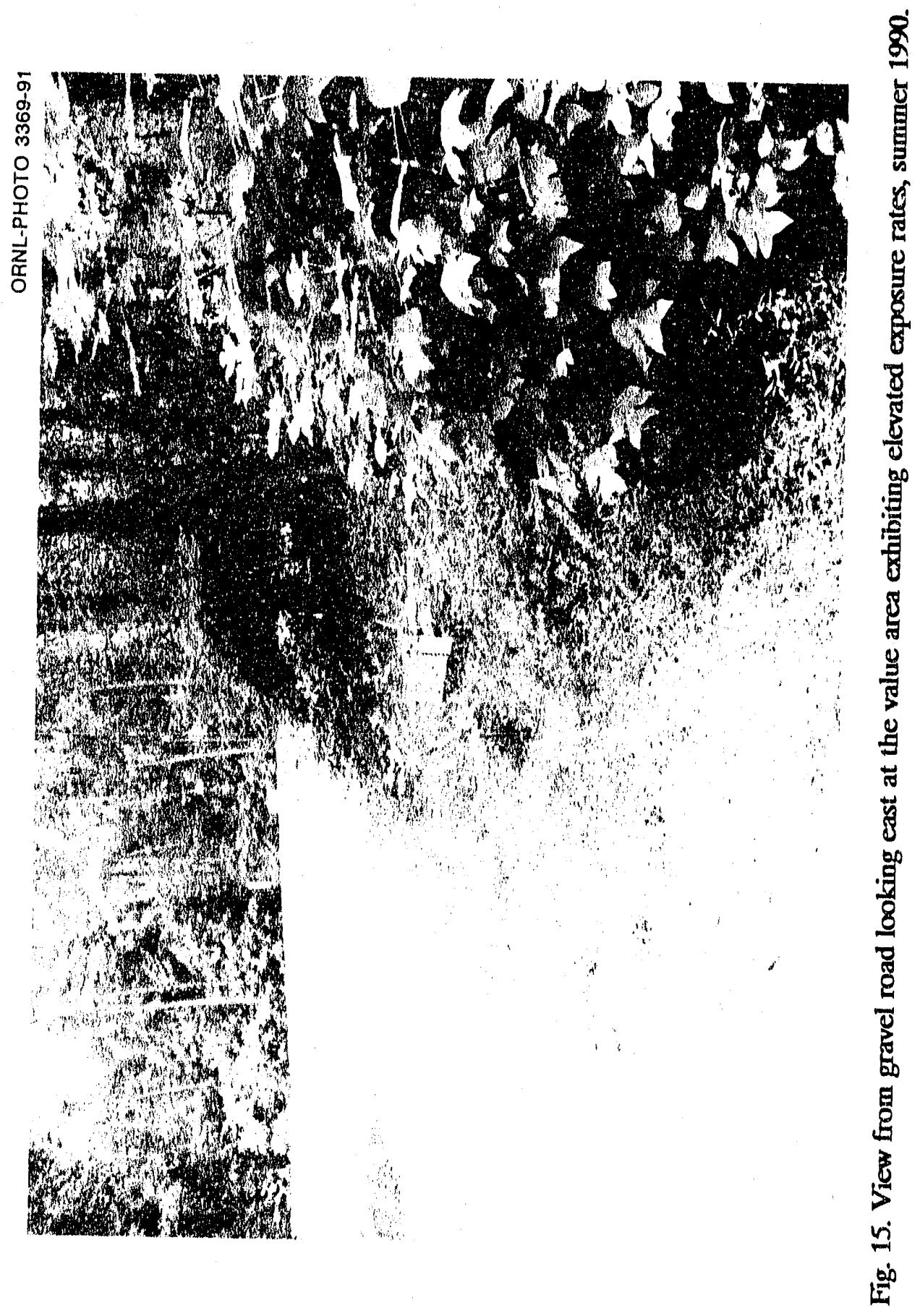




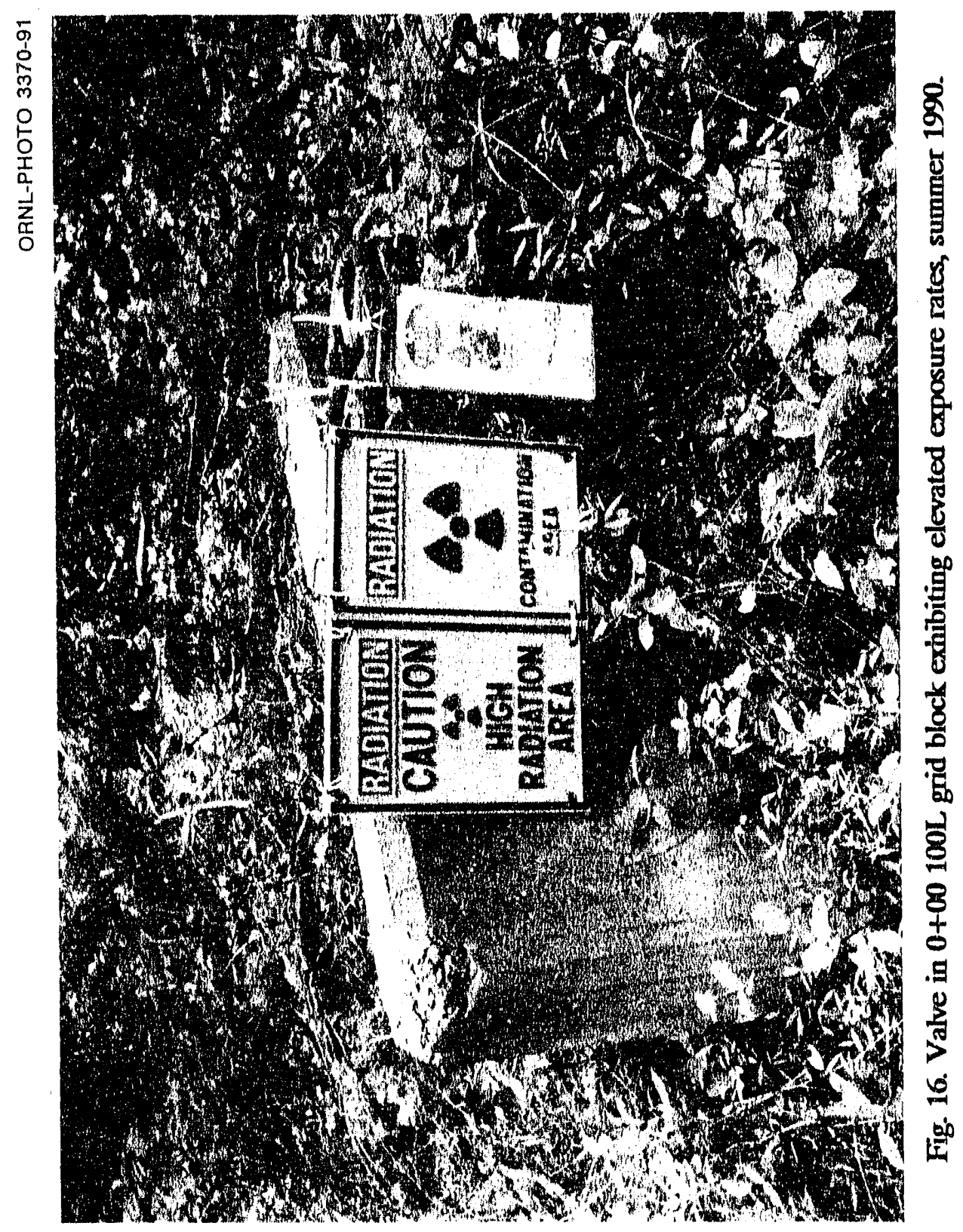


arranged in this format, a linear least-squares regression would provide new parameter estimates. An inverse regression would be necessary to predict exposure rate from the observed scintillator count rate. By rearranging Eq. (2),

$$
\underline{\imath}=\frac{y_{0}-b_{0}}{b_{1}} \text {, }
$$

where the variables are identical to those in $\mathrm{E}$ (1. (2), except that the predicted $x$ is now a function of the observed $y$. Confidence limits for the predicted input variable are available as well. Draper and Smith (1981) show that the lower and upper confidence bounds for the predicted input are the roots of a quadratic equation containing quantities used in the regression calculations. Problems can arise as a result of a poorly determined regression, when $\left|b_{1}\right|$ is small or when its standard deviation is large. In such cases the roots may be negative or both lie on one side of the predicted $x$, which occurs when one or both of the confidence bounds for the regression are sharply hyperbolic in the region of interest.

For a more complete characterization, unbounded by the limited resources of time and money, biased soil samples should be taken at every point and area exhibiting elevated exposure rates. Additional systematic samples should also be analyzed to more precisely determine the background concentrations of radionuclides. 


\section{REFERENCES}

Baes, C. F., Jr. and R. E. Mesmer. 1976. The Hydrolysis of Cations. John Wiley and Sons, New York. Cited in Onishi et al. 1981.

Carrigan, P. H., Jr. 1968. Radioactive Waste Dilution in the Clinch River Eastern Tennessee. U.S. Gcol. Survey Prof. Paper 433-G, pp. 61-69. Cited in Onishi et al. 1981.

Carrigan, P. H., Jr, 1969. Inventory of Radionuclides in Bottom Sediment of the Clinch River Eastern Tennessee. U.S. Geol. Survey Prof. Paper 433-I 18 p. Cited in Onishi et al. 1981.

Carrigan P. H., Jr., R. J. Pickering, T. Tamura, and R. Forbes. 1967. Radioactive Materials in Bottom Sediment of Clinch River: Part A, Investigations of Radionuclides in Upper Portion of Sediment. ORNL-3721 (Suppl. 2A). Cited in Onishi et al. 1981.

Charlot G. 1957. Qualitative Analysis and Solution Reactions. 4th Edition. Masson, Paris. Cited in Onishi et al. 1981.

Codell, R. B., and J. D. Duguid, 1983. "Transport of Radionuclides in Groundwater," in Radiological Assessment: A Textbook on Environmental Dose Analysis. Till, J. E. and H. R. Meyer, eds. NUREG/CR-3332.

Coobs, J. H., and J. R. Gissel. 1986. History of Disposal of Radioactive Wastes into the Ground at Oak Ridge National Laboratory. ORNL/TM-10269.

Davis, D. M., and E. D. Gupton. 1969. Health Physics Instrument Manual. ORNL-332 (Revised).

Draper, N. R., and H. Smith. 1981. Applied Regression Analysis. John Wiley and Sons, New York.

Izracl, Y. A., and F. Y. Rovinsky. 1970. Hydrological Uses of Isotopes Produced in Underground Nuclear Explosions for Peaceful Purposes. UCRL-Trans-10458. Cited in Onishi et al. 1981.

Jenne, E. A., and J. S. Wahlberg. 1968. Role of Certain Stream-Sediment Components in Radioion Sorption. U.S. Geol. Survey Prof. Paper 433. F. Cited in Onishi et al. 1981.

Lammers, W. T. 1968. The Distribution of ${ }^{60} \mathrm{Co},{ }^{106} \mathrm{Ru}$, and ${ }^{137} \mathrm{Cs}$ Among Suspended and Dissolved Particles in White Oak Lake. K-1758.

Lomenick, T. F., D. G. Jacobs, and E. G. Struxness. 1967. "The Behavior of Strontium-90 and Cesium-137 in Secpage Pits at ORNL," Health Phys. 13:897-905.

Lomenick, T. F., and T. Tamura. 1965. "Naturally Occurring Fixation of ${ }^{137} \mathrm{Cs}$ on Sediments of Lacustrine Origin," Soil Sci. Soc. Amer. Proc. 29:383-7. Cited in Onishi et al. 1981.

Myrick, T. E., B. A. Berven, W. D. Cotrell, W. A. Goldsmith, and F. F. Haywood. 1987. Procedures Manual for the ORNL Radiological Survey Activities (RAjA) Program. ORNL/TM-8600.

Onishi, Y., R. J. Serne, and E. M. Arnold. 1981. Critical Review: Radionuclide Transport, Sediment Transport, and Water Quality Mathematical Modeling; and Radionuclide Adsorption/Desorption Mechanisms. NUREG/CR-1322.

Pickering, R. J. 1970. Composition of Water in Clinch River, Tennessee River, and White Oak Creek as Related to Disposal of Low-Level Radioactive Liquid Wastes. U.S. Geol. Survey Prof. Paper 433-O, 15 p. Cited in Onishi et al. 1981.

Pickering, R. J., P. H. Carrigan, Jr., and F. L. Parker. 1965. The Clinch River Study - An Investigation of the Fate of Radionuclides Released to a Surface Stream. Geological 
Survey Clrcular 497. Cled in Onishi et al. 1981.

Pickering, R. J., P. H. Cartigan, T. Tamura, H. H. Abec, J. W. Beverage, and R. W. Andrew. 1966. Radioactivity in Botlom Sediments of the Clinch-Tennessee Rivers. IAEA-SM-72/4. Citod in Onishl ot ul. 1981.

Ross, S. M. 1987. Introduction to Probability and Statistics for Engineers and Scientists. John Wiley and Sons, New York.

Vinogradov, A. P. 1959. The Geochemistry of Rare and Dispersed Chemical Elements in Soils. Consultants Burcau, Inc. Cited in Onishi et al. 1981. 
I

I

I

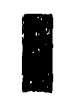

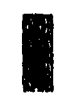

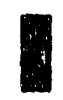

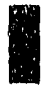

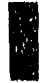

i 
The most well-known publication in the radiation protection lield is the Health Physics Journal. Instructions to contributors are published periodically regarding the usage of units in submitted manuscripts (see Health Phys. 58:769-771). To adhere to the conventions adopted by the Health Physics Journal, all units associated with quantitics reported in this document will use the approved SI units.

In many instances ORNL provides quantities in the traditional system. When this occurs, the quantity is converted to its SI equivalent. The original number and unit is then given parenthelically. In some cases where quanities with SI units are already normally employed, no such parenthetical appendage is given; only the SI quantity appears.

Conversion factors for basic and derived units are readily available. Values given in the CRC Handbook of Radiation Measurement and Protection (Brodsky 1978) were used in the data analyses. Units and conversion factors that deal specifically with radiation and its associated phenomena are given in ICRU Report 33 (1980). Table A.1 summarizes units and conversions used in this document.

The Health Physics Journal also approves several nonstandard units for use in ectain contexts (sec Health Phys. 56:1-7). Units of time need not appear as seconds; minutes, hours, days, etc., are all aceeptable. Square ecntimeters may be used when the use of square meters is impractical. Volumes, normally expressed as cubic meters, may appear as liters, such that $1 \mathrm{~L}=10^{3} \mathrm{~m}^{3}$. 

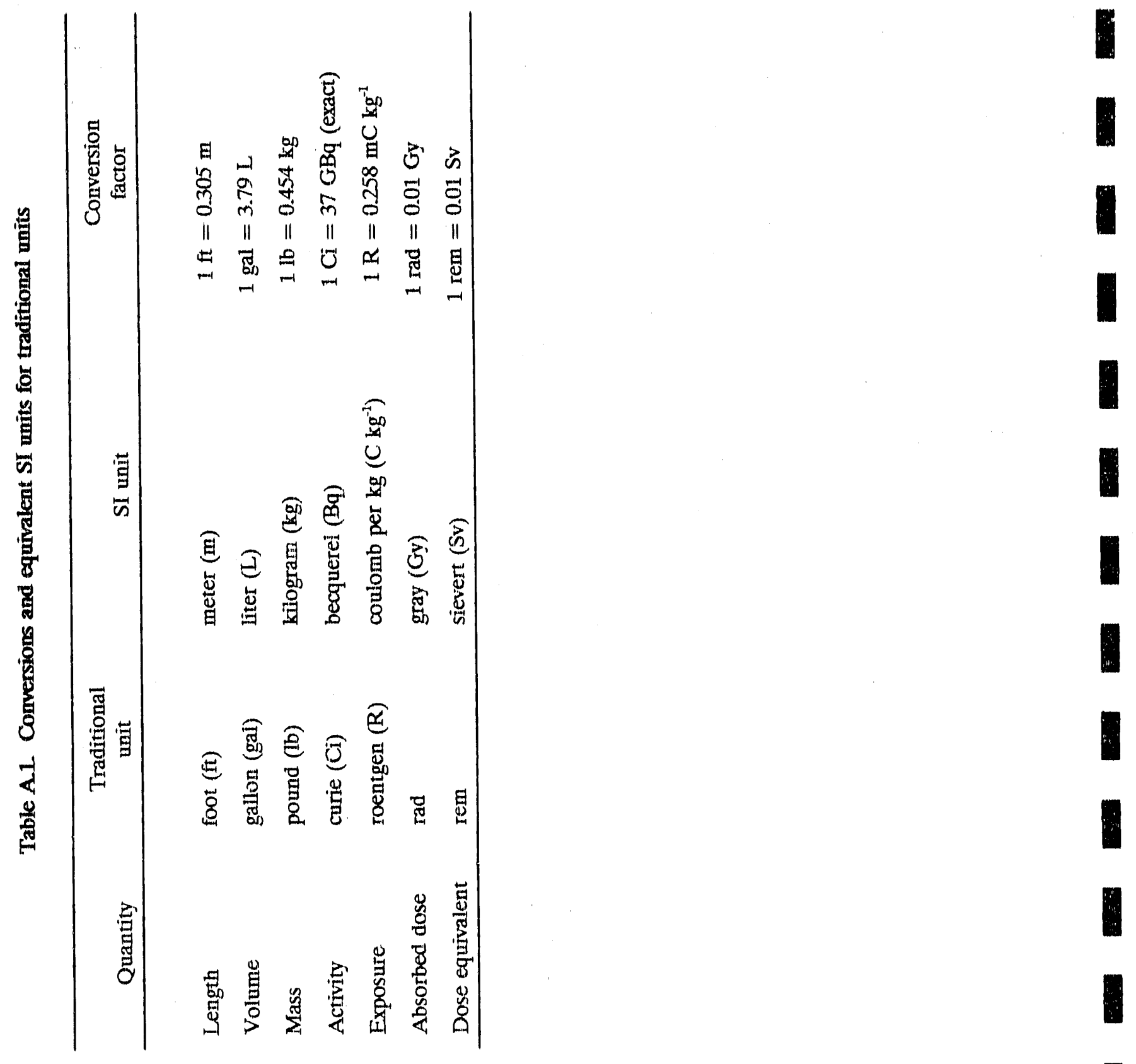


\section{APPENDIX A REFERENCES}

Brodsky, A. B., ed. 1978. CRC Handbook of Radiation Measurement and Protection. Section A: Volume I. CRC Press, West Palm Beach, FL.

International Commission on Radiation Units and Moasurements. 1980. Radiation quantities and units: ICRU REPORT 33. International Commission on Radiation Units and Measurements, Washington, DC.

Turner, J. E. 1986. Atoms, Radiation, and Radiation Protection. Pergamon Press, New York.

U.S. Environmental Protection Agency, 1980. Prescribed Procedures for Measurement of Radioactivity in Drinking Water. EPA 600 4-80-(032. p. 58-69. 


\section{B.1 INTRODUCTION}

The strontium analyses were performed by ORNL's Analytical Chemistry Division. The chemical treatment and the counting of the samples submitted were carricd out in accordance with EPA guidelines. This appendix is a summary of the guidelines set forth in EPA 600480 032, Prescribed Procedures for Measurement of Radioactivity in Drinking Water (USEAP 1980).

Although the submitted samples were in soil and vegetable matrices rather than in drinking water, the procedures still apply. The samples, which had been radioactively decaying for about 25 years, were treated as described here so that acidic solutions representative of the original samples could then undergo the strontium analyses.

Each sample was carefully weighed. The soil sample was then leached with nitric acid, and the leachate was treated. The two vegetable samples were first ashed at a high temperature in a muflle furnace for approximately $12 \mathrm{~h}$. The resulting ash was dissolved in nitric acid and treated as described in the following. In each case, the nitric acid solution had a $\mathrm{pH}$ of $<2$ and contained a precisely known weight of the sample.

During the 25 -year storage period, any ${ }^{89} \mathrm{Sr}$ that may have been stored would have decayed to the point of not contributing significantly to the strontium activity of any sample. The half-life of ${ }^{89} \mathrm{Sr}$ is roughly $52 \mathrm{~d}$; thus, 25 years represents approximately 175 half-lives, which is sufficient time for the species to decay almost completely. On the other hand, ${ }^{90} \mathrm{Sr}$, with its 28 -year half-life, would still exhibit appreciable activity.

\section{B.2 METHOD SUMMARY}

The method used measures total strontium and soluble ${ }^{89} \mathrm{Sr}$ and ${ }^{91} \mathrm{Sr}$ in drinking water (and, in this case, in a nitric acid solution). Some insoluble strontium may also be included. Because only the total strontium activity was being quantified, only this portion of the method is included in this summary.

A known quantity of strontium carrier was prepared and added to the aliquot to be treated. The carrier determined the chemical yield of the process without contributing to the beta count. Strontium in the solution was then precipitated as a carbonate. Several other soluble elements present also precipitated as carbonates and were subsequently removed. Calcium and other elements were eliminated by precipitating the strontium again, this time as a nitrate. Barium and radium were then removed by precipitating them as chromates. The ${ }^{97} \mathrm{Y}$ daughter of ${ }^{90} \mathrm{Sr}$ was separated as a hydroxide precipitate.

Steps from this point on $w$ "ce carricd out without delay 10 minimize yttrium ingrowth and to minimize contact with air. Such contact could result in deposition of radon daughters that might obscure the strontium activity. Because the remaining strontium nuclides had long half-lives relative to the time required to perform the remaining steps (approximately $2 \mathrm{~h}$ ), the ingrowth of daughter activity was negligible. 
The resulting strontium carbonate compound was washed, dried, and weighed. Counting was performed in a gas-flow proportional counter.

\section{B.3 CALCULATIONS}

Equation (10) gives the total strontium activity (in picocuries).

$$
A=\frac{R}{0.037 E Y M},
$$

where

$A=$ strontium activity $\left(\mathrm{pCi} \mathrm{kg}^{-1}\right)$,

$R=$ net count rate (cpm),

$E=$ counter efficiency for ${ }^{90} \mathrm{Sr}\left(\mathrm{cpm} \mathrm{Bq}{ }^{-1}\right)$,

$Y=$ chemical yield of strontium,

$M=$ mass of original sample $(\mathrm{kg})$,

$0.037=$ exact conversion factor $\left(\mathrm{Bq} \mathrm{pCi}^{-1}\right)$.

To convert to becquerels (for inclusion in this document), the conversion factor was omitted.

Because no ${ }^{89} \mathrm{Sr}$ is present, the ${ }^{90} \mathrm{Sr}$ counting efficiency is appropriate. A National Institute of Science and Technology traceable ${ }^{90} \mathrm{Sr}$ standard is used to determine this factor.

The chemical yieid is a factor that takes into account the unfortunate fact that less than $100 \%$ of the strontium in the sample is recovered in the final compound; that is, each reaction in the process does not go to completion. This factor is determined through the use of the strontium carrier as follows:

$$
Y=\frac{C}{B}
$$

where

$Y=$ chemical yield,

$C=$ mass of $\mathrm{SrCO}_{3}$ recovered $(\mathrm{mg})$.

$B=$ mass of $\mathrm{Sr}$ carrier added (mg as carbonate).

Because of the stochastic nature of radioactive decay, there is an uncertainty associated with this or any count. This uncertainty is measured by the standard deviation of the count as calculated below:

$$
\sigma=\left[\frac{R}{t_{g}}+\frac{B}{t_{b}}\right]^{\frac{1}{2}},
$$

where 
$\boldsymbol{\sigma}=$ standard deviation $(\mathrm{cpm})$

$R=$ gross cc 'nt rate $(\mathrm{cpm})$,

$t_{g}=$ gross count time $(\mathrm{m})$,

$B=$ background count rate (cpm),

$t_{b}=$ background count time $(\mathrm{m})$.

The uncertainty reported for these calculations is a two-sigma error. That is, it is twice the standard deviation as given in Eq. 12. Although counting statistics are Poisson distributed, the central limit theorem allows a normal approximation of this distribution at counts above about 30 . On a normally distributed random variable (as is the case here), two standard deviations correspond to approximately a 95\% confidence interval (Turner 1986). 
ORNL/ER-35

\section{DISTRIBUTION}

1. L. V. Asplund/N. W. Durfec

2. C. F. Baes III

3. L. D. Bates

4. B. A. Berven

5. H. M. Braunstein

6-7. T. W. Burwinkle

8. H. M. Butler

9. R, F. Carrier

10-11. K. W. Cook

12. W. D. Cottrell

13. F. K. Edwards, Jr.

14. R. D. Foley

15. M. K. Ford

16-17. H. R. Gaddis

18. S. B. Garland II

19. C. T. Garten, Jr.

20. C. D. Goins

21-24. L. Holder, Jr.

25. D. D. Huff

26. L. D. Hyde

27. R. L. Jeffers

28. R. G. Jones

29. S. V. Kaye

30. R. H. Ketelle

31. A. J. Kuhaida, Jr.

32. J. R. Lawson

33. D. W. Lee

34. L. E. McNeese
35. C. E. Nix

36-37. P. T. Owen

38. P. F. Reeverts

39. R. E. Rodriguez

40. P. S. Rohwer

41. T. H. Row

42. G. E. Rymer

43. T. F. Scanlan

44. P. A. Schrandt

45. B. P. Spalding

46-51. R. E. Siwaja

52. J. H. Swanks

53. D. W. Swindle

54. P. F. Tiner

55-56. J. R. Ttabalka

57. M. S. Uziel

58. C. K. Valentine, Jr.

59. J. E. Van Cleve, Jr.

60. L. D. Voorhees

61. R. K. White

62-66. J. K. Williams

67-72. MAD Records Center

73. Central Research Library

74. ORNL Technical Library, Y-12

75-76. Laboratory Records Dept.

77. ORNL Patent Section

78-82. ER Document Management Center

83. Office of Assistant Manager for Energy Research and Development, DOE Ficld Office, Oak Ridge, P.O. Box 2001, Oak Ridge, TN 37831-8600

84-85. J. R. Kannard, Program Manager, Bechtel National, Inc., P.O. Box 350, Oak Ridge Corporate Center, 151 Lafayette Drive, Oak Ridge, TN 37831-0350

86. P. H. Edmonds, Radian Corporation, 120 South Jefferson Circle, Oak Ridge, TN 37830

87-90. W. E. Murphie, Department of Energy, Office of Environmental Restoration, Eastern Area D\&D Branch, EM-423 (GTN), Washington, DC 20545

91-92. S. S. Perkins, DOE Field Office, Oak Ridge, Information Resource Center, 105 Broadway, Oak Ridge, TN 37830

93-94. S. P. Riddle, DOE Ficld Office, Oak Ridge, P.O. Box 2001, Oak Ridge, TN 37831-8541

95-96. R. C. Sleeman, DOE Ficld Office, Oak Ridge, P.O. Box 2001, Oak Ridge, TN 37831-8541

97-98. Office of Scientific and T'cchnical Information, P.O. Box 62, Oak Ridge, TN 37831 


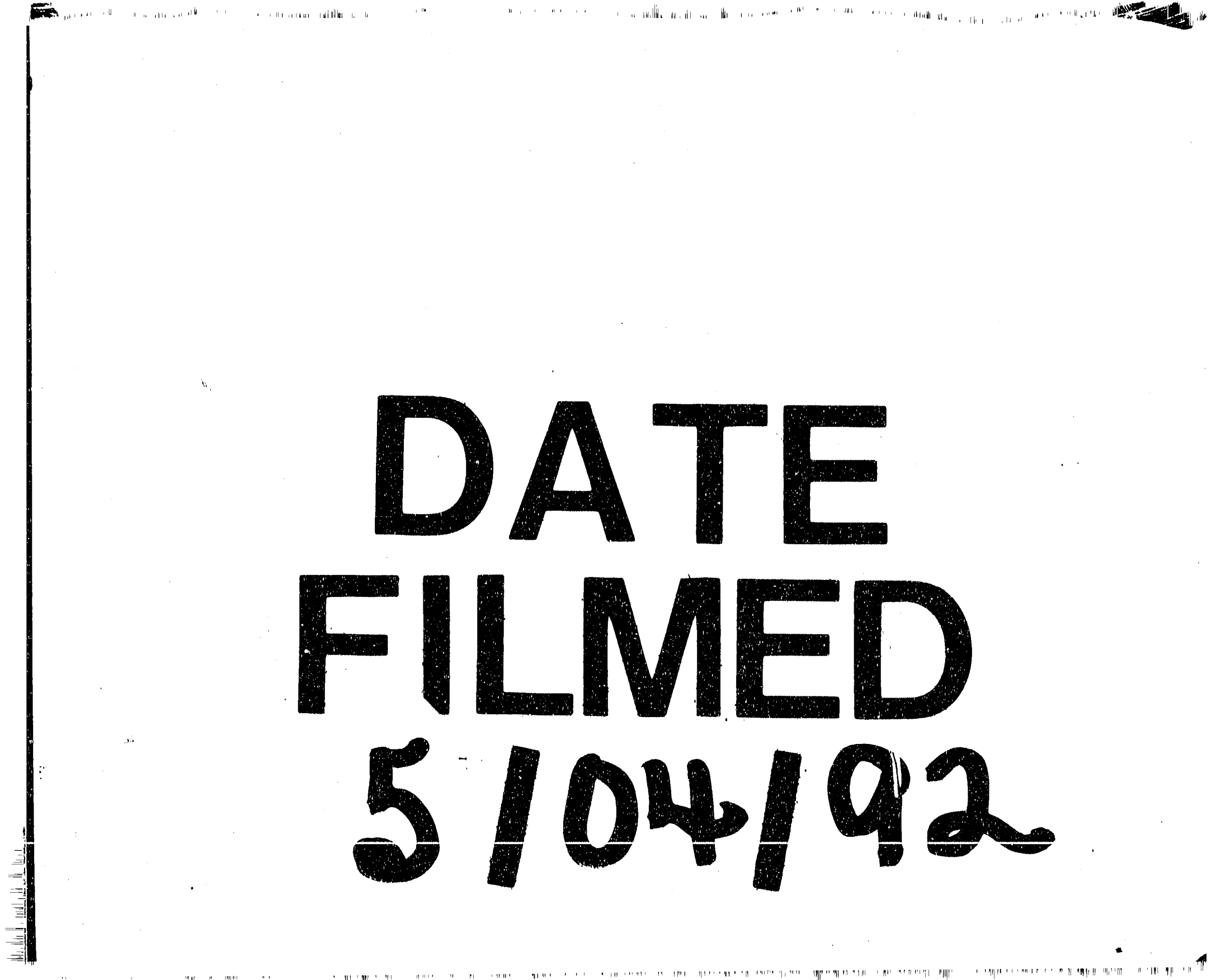




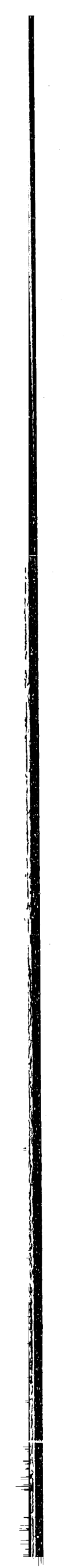

